\title{
1 Vegetation-wave interactions in salt marshes under storm surge
}

2

3

4

5

6

7

8

9

10

11

12

13

\section{conditions}

Rupprecht $\mathrm{F}^{1^{*}}$, Möller $\mathrm{I}^{2,3}$, Paul $\mathrm{M}^{4,8}$, Kudella $\mathrm{M}^{4}$, Spencer $\mathrm{T}^{2}$, van Wesenbeeck $B K^{5,6}$, Wolters $\mathrm{G}^{5}$, Jensen $\mathrm{K}^{1}$, Bouma $\mathrm{TJ}^{7}$, Miranda-Lange $\mathrm{M}^{4}$ \& Schimmels $\mathrm{S}^{4}$.

${ }^{1}$ Applied Plant Ecology, Biocenter Klein Flottbek, University of Hamburg, Ohnhorststr. 18, 22609 Hamburg, Germany

${ }^{2}$ Cambridge Coastal Research Unit, Department of Geography, University of Cambridge, Downing Place, Cambridge CB2 3EN, UK

${ }^{3}$ Fitzwilliam College, Storey's Way, Cambridge CB3 ODG, UK

${ }^{4}$ Forschungszentrum Küste (FZK), Merkurstr. 11, 30419 Hannover, Germany

${ }^{5}$ Deltares, Boussinesqweg 1, 2629 HV Delft, Netherlands

${ }^{6}$ Department of Hydraulic Engineering, Delft University of Technology, P.O. Box 5048, 2600 GA Delft, The Netherlands

${ }^{7}$ Yerseke Spatial Ecology, Netherlands Institute for Sea Research (NIOZ), Korringaweg 7, 4401 NT, Yerseke, Netherlands

8 present address: Environmental Systems Analysis, Institute of Geoecology, Technische Universität Braunschweig, Langer Kamp 19c, 38106 Braunschweig, Germany

\section{${ }^{*}$ Corresponding author. E-mail address: franziska.rupprecht@uni-hamburg.de,} Phone: +49 (0)40-42816-272 
41 Highlights

- Salt marsh vegetation can reduce near-bed orbital velocities during storm surges

43 - Vegetation effect on orbital velocities varies with biophysical properties

$44 \quad$ - Flexible low-growing plant canopies show high resilience to storm surge conditions

45 - More rigid and tall grasses experience stem folding and breakage

$46 \quad-\quad$ The contribution of vegetation to wave dissipation is plant species specific 


\section{Abstract}

Vegetation-wave interactions are critical in determining the capacity of coastal salt marshes to reduce wave energy (wave dissipation), enhance sedimentation and protect the shoreline from erosion. While vegetation-induced wave dissipation is increasingly recognized in low wave energy environments, little is known about: i) the effect of vegetation on wave dissipation during storms when wave heights and water levels are highest; and ii) the ability of different plant species to dissipate waves and to maintain their integrity under storm surge conditions. Experiments undertaken in one of the world's largest wave flumes allowed, for the first time, the study of vegetation-wave interactions at near-field scale, under wave heights ranging from $0.1-0.9 \mathrm{~m}$ (corresponding to orbital velocities of $2-91 \mathrm{~cm} \mathrm{~s}^{-1}$ ) and water depths up to $2 \mathrm{~m}$, in canopies of two typical NW European salt marsh grasses: Puccinellia maritima (Puccinellia) and Elymus athericus (Elymus). Results indicate that plant flexibility and height, as well as wave conditions and water depth, play an important role in determining how salt marsh vegetation interacts with waves. Under medium conditions (orbital velocity $42-63 \mathrm{~cm} \mathrm{~s}^{-1}$ ), the effect of Puccinellia and Elymus on wave orbital velocities varied with water depth and wave period. Under high water levels ( $2 \mathrm{~m}$ ) and long wave periods $(4.1 \mathrm{~s})$, within the flexible, low-growing Puccinellia canopy orbital velocity was reduced by $35 \%$ while in the more rigid, tall Elymus canopy deflection and folding of stems occurred and no significant effect on orbital velocity was found. Under low water levels $(1 \mathrm{~m})$ and short wave periods (2.9 s) by contrast, Elymus reduced near-bed velocity more than Puccinellia. Under high orbital velocities $\left(\geq 74 \mathrm{cms}^{-1}\right)$, flattening of the canopy and an increase of orbital velocity was observed for both Puccinellia and Elymus. Stem folding and breakage in Elymus at a threshold orbital velocity $\geq 42$ $\mathrm{cm} \mathrm{s}^{-1}$ coincided with a levelling-off in the marsh wave dissipation capacity, while Puccinellia survived even extreme wave forces without physical damage. These findings suggest a species-specific control of wave dissipation by salt marshes which can potentially inform predictions of the wave dissipation capacity of marshes and their resilience to storm surge conditions.

Key words: Wave dissipation; Flow reduction; Coastal wetlands; Biophysical plant properties; Plant breakage; Vegetation resilience; Wave flume experiment 


\section{Introduction}

The interaction of vegetation with currents and waves affects a wide range of ecosystem functions of coastal salt marshes including the reduction of hydrodynamic energy, sediment deposition and erosion and carbon storage (Duarte et al., 2013; McLeod et al., 2011; Möller et al., 1999; Temmerman et al., 2005).

Most knowledge on flow dynamics in and around salt marsh canopies has been acquired under average hydrodynamic conditions. Field studies have shown a reduction of both unidirectional and wave-induced oscillatory flow within plant canopies that can lead to a decline in bed shear stress and erosion and promote sedimentation (Leonard and Croft 2006; Neumeier and Amos 2006a; Neumeier and Amos 2006b; Peralta and others 2008). Flume and numerical modelling studies have highlighted the importance of plant posture and motion as a mechanism for the vegetation-mediated reduction of water velocity and hydrodynamic energy (Bouma and others 2005; Dijkstra and Uittenbogaard 2010; Luhar and Nepf 2011; Luhar and Nepf 2016; Mullarney and Henderson 2010). When waves advance over a vegetated marsh surface, and water depths are low enough to allow wave-induced oscillatory flow to penetrate into the canopy layer, vegetation interacts with this flow and provides flow resistance. In return, the vegetation experiences drag and re-orientation by wave forces (Mullarney and Henderson 2010). The drag caused by plants causes a reduction of wave orbital velocities and thus wave height and energy (wave dissipation).

Knowledge of this wave dissipation function has generated high interest in the use of vegetated ecosystems, such as salt marshes, as a cost-effective element of coastal protection schemes. Furthermore, the ability of marshes to track rising water levels as a result of the positive feedbacks between vegetation growth and marsh accretion suggests sustainable protection under accelerated sea level rise (Kirwan and others 2016). However few empirical observations of vegetation-wave interactions exist, especially during storm surges when water levels and waves are highest and large amounts of sediments are mobilized (Cahoon 2006; Stumpf 1983; Turner and others 2006). I Hence it is not clear how canopies of different salt marsh plants vary in their ability to reduce wave orbital velocities and thus in their contribution to wave dissipation and erosion protection.

Detailed insights into vegetation-wave interactions are of major importance for salt marsh conservation and management aiming to maximize the sea defence value of marshes as well as for the generation of reliable predictions of the marsh wave dissipation capacity and marsh resilience to storm events. Only with this knowledge will it be possible to successfully incorporate marshes into coastal defense schemes (Anderson and Smith 2014; Bouma and others 2014; Möller and others 2014). 
Vegetation-wave interactions, and the resulting wave dissipation, are a function of biophysical plant properties such as flexibility, density, biomass and height as well as hydrodynamic conditions such as incident wave height, wave period and water depth (Anderson and others 2011; Paul and others 2016).

Plant flexibility determines how much, and in what way, plants move and hence the magnitude of drag forces experienced (Luhar and Nepf 2016; Mullarney and Henderson 2010; Paul and others 2016). Under wave forcing two types of plant movement need to be distinguished:

Swaying is an oscillatory plant movement throughout the wave cycle with symmetric bending in the both directions of water flow under wave motion. Whip-like movement is characterized by a fast flipping over from a short backward bending of the plants, to an extended 'forward' bending and wide stem extension in the dominant direction of wave-induced oscillatory flow (in general the direction of wave travel). The latter motion results in flattening of the canopy, a loss of flow resistance and high orbital velocity for part of the wave cycle. A transition from swaying to whip-like movement can occur for a species when wave height and energy increases, with the point of transition depending on the stiffness of the plant and the ratio of plant height to wave orbital excursion (Manca 2010; Paul and others 2012).

Numerical models simulating the motion of flexible aquatic vegetation under wave orbital velocities use primarily two dimensionless parameters to describe plant movement and predict drag forces acting on vegetation: (i) the Cauchy number, $\mathrm{Ca}$, which represents the ratio of the hydrodynamic forcing to the restoring force due to plant stiffness; and (ii) the ratio of plant height to wave orbital excursion, $L$ (Luhar and Nepf 2016). A value of $C a<1$ implies an upright plant posture under wave-induced oscillatory flow, as hydrodynamic forces are much smaller than the restoring force due to stiffness. When $\mathrm{Ca}>1$, plants start to bend with increasing values of $\mathrm{Ca}$ indicating a decrease of flow resistance and drag acting on vegetation due to increasing plant bending under wave forces. For $L>1$, a swaying plant movement with moderate bending angles can be assumed. When $L<1$, the high orbital velocities are expected to cause an extended 'forward' bending and a flattening of the canopy and low flow resistance for part of the wave cycle (Luhar and Nepf 2016), i.e. a plant behaviour typically occurring under a whip like canopy movement. For flexible aquatic vegetation the buoyancy parameter $B$, representing the ratio of restoring forces due to buoyancy and stiffness, also affects plant bending (Luhar and Nepf 2011). However, $B$ can be neglected in the case of the terrestrial salt marsh plants that exhibit high stiffness compared to seagrasses or macroalgae (Rupprecht et al., 2015a).

Salt marsh plants show a wide variability of stem flexibility, both between different species and the different stem parts of specimens of one species. Little is known on how this variability affects vegetation-wave interactions (Rupprecht and others 2015a). Previous studies on plants of tidal 
marshes (Bouma and others 2005; Heuner and others 2015; Silinski and others 2015) but also on freshwater macrophytes (Aberle and Jarvela 2013; Robionek and others 2015; Sand-Jensen 2003) and macroalgae (Gaylord and Denny 1997; Stewart 2006) have shown that drag experienced by plants under hydrodynamic forcing is inversely related to their flexibility. Flexible plants show an avoidance strategy and minimize the risk of folding and breakage through reconfiguration; stiff plants by contrast maximize the resistance to physical damage (tolerance strategy) but may break if hydrodynamic forces increase beyond a critical level (Heuner and others 2015; Puijalon and others 2011; Silinski and others 2015). For plants characterized byswaying movement, a positive correlation between stem stiffness and vegetation-induced wave dissipation has been observed (Bouma and others 2005). When comparing two salt marsh grasses with different stem flexibility and stem density, Bouma et al. (2010) found that an increase in stem density and biomass can counteract the reduced wave dissipation capacity of flexible plants.

Apart from stem flexibility, density and biomass, the wave dissipation capacity of salt marsh canopies is affected by the ratio of water depth to canopy height (submergence ratio) (Möller and others 1997; Möller and others 1999; Yang and others 2012). The effectiveness of vegetation in dissipating waves has been shown to increase with the percentage of the water column that it occupies, i.e. with decreasing submergence ratio (Augustin et al., 2009; Paul et al., 2012)..

Beyond a critical combination of orbital velocities and water depth, changes in type and magnitude of vegetation-wave interactions are likely to result in a significant alteration of vegetation-induced wave dissipation. The existence of hydrodynamic thresholds determining the transition from wave regimes with vegetation-induced wave modification and wave dissipation to those regimes characterized by a flexing, folding or breakage of plants under wave orbital velocities and a decline in vegetation-induced wave dissipation has been suggested by various authors (Gedan et al., 2011; Koch et al., 2009; Möller et al., 1999; Yang et al., 2012), but remains to be demonstrated. This is because the quantification of such hydrodynamic thresholds either by field studies, flume experiments or by numerical modelling is extremely challenging. Field studies suffer from the unpredictable nature and high temporal variability of wave conditions and difficulties in deploying instrumentation under higher energy wave events. Laboratory flume studies offer controlled wave conditions, but are often hampered by limits to the water depths and waves that can be generated. It has proved difficult to build realistic small-scale physical models of vegetated surfaces (Fonseca and Cahalan 1992; Mendez and Losada 2004).

Numerical models of wave dissipation can simulate a wide range of wave conditions (Mendez and Losada 2004; Riffe et al., 2011) but in the absence of suitably representative flume or field calibration data suffer from the difficulty of realistically representing vegetation as well as its effect on wave orbital velocities. 
In this paper we report results from a unique experiment on wave dissipation over coastal salt marshes conducted in one of the world's largest wave flumes at a near field scale (for details see Möller et al., 2014). We analyzed vegetation-wave interactions in canopies of two salt marsh grasses, the low growing and flexible Puccinellia maritima and the tall, less flexible Elymus athericus, over a wide range of wave conditions and corresponding orbital velocities to answer the following questions:

(1) How do plant canopies of different biophysical properties (flexible and low-growing vs. stiff and tall) affect wave orbital velocities under rising wave energy and water depths?

(2) Does physical damage to vegetation under increasing wave energy differ between flexible, low-growing canopies and stiff, tall canopies? If so - is there a threshold in orbital velocity beyond which differences in plant susceptibility to folding and breakage become apparent?

\section{Methods}

\subsection{Study species and biophysical properties}

We investigated two grasses commonly occurring in NW European salt marshes, Puccinellia maritima (Hudson) Parl. and Elymus athericus L.; hereafter referred to as Puccinellia and Elymus(Fig. 1). Puccinellia is typical of marshes at low to mid elevations in the tidal frame and characteristic of earlyto mid-successional stages of salt marsh vegetation development. Where sandy soils are present, it can also be found in the lower-lying pioneer zone. Puccinellia is also a characteristic species of grazed salt marshes, as the species is tolerant to trampling, biomass loss and waterlogging and can reproduce by clonal growth.

In contrast to Puccinellia, Elymus needs aerated soils and is sensitive to grazing. In many salt marshes of NW Europe, it forms monospecific dense stands in the high marshes and represents a latesuccessional stage of salt marsh vegetation. In recent decades, Elymus has rapidly colonized mainland salt marshes along the North Sea coast and the Atlantic coast where it can be found not only in the high marsh but also in mid and sometimes low marshes (Bockelmann and Neuhaus 1999; Valéry et al., 2004). The expansion of Elymus has been related to the abandonment of grazing, high vertical accretion rates and marsh age as well as the species ability to reproduce clonally by rhizomes (Rupprecht et al., 2015b; Veeneklaas et al., 2013).

Puccinellia and Elymus differ with respect to their biophysical properties, such as plant stem flexibility, stem density and stem height, which have relevance for flow and wave dissipation. Puccinellia canopies are characterized by a high stem flexibility, high stem density and low canopy 
height (around $0.2 \mathrm{~m}$, Table 1). Canopies of Elymus show a low stem flexibility and stem density and a canopy height (around $0.8 \mathrm{~m}$ ) that is four times greater than that of Puccinellia (Table 1). Previous measurements of stem flexibility in salt marsh grasses have shown that variation of stem flexibility between the bottom (more rigid) and the middle and top (more flexible) stem parts of Elymus is much higher than in Puccinellia (Rupprecht et al., 2015a).

As measures of stem flexibility, the Young's bending modulus and flexural rigidity of Puccinellia and Elymus stems were determined of 17 and 18 samples, respectively, using a three-point-bending test ( for methodology see Rupprecht et al. (2015a)). Prior to performing the tests, stem length up to the onset of the youngest leaf was measured and stems were divided into three equal parts (bottom, middle, top). The test section was cut from the middle of each part of the stem.

Stem height was measured with a folding rule for 30 randomly chosen stems. Stem density of Elymus was measured by counting the number of stems in 15 quadrats of a size of $20 \times 20 \mathrm{~cm}$ randomly distributed across the vegetated test section in the flume. For Puccinellia, the very high stem density $\left(\mathrm{N} / \mathrm{m}^{2}>1000\right)$ and the low stem diameter meant that a quantitative assessment of stem density was not feasible in the framework of the present study.

We compared biophysical properties of the Puccinellia and the Elymus canopy between the flume test section and the field site from where the salt marsh for the flume experiment was excavated (see also section 2.2). No statistical difference was found in the Young's bending modulus; t-test; $p$ > 0.05. However flexural rigidity of Puccinellia and Elymus stems was significantly lower in the flume than in the field (t-test; $p<0.01$ ). This indicates that stems of Puccinellia and Elymus in the flume were more flexible than stems at the field site, when accounting for varying stem diameter. The lower nutrient supply and less mechanical stress experienced during the one year storage period of the vegetation prior to the start of the experiment (for detailed information see Möller et al., 2014), as compared to the regular flood of in situ marshes, may explain these differences.

Stem height of Puccinellia was significantly higher in the flume than in the field (t-test; $p<0.05$ ). For Elymus, no significant differences of stem height and stem density were found between the flume and the field site (t-test; $p>0.05$ ).

\#Figure 1

\#Table 1

\subsection{Experimental set-up}

The study was carried out in conjunction with an experiment on wave dissipation over natural salt marsh transplants under storm surge conditions (Möller et al., 2014). This experiment was conducted in the $5 \mathrm{~m}$ wide, $7 \mathrm{~m}$ deep and approx. $310 \mathrm{~m}$ long Large Wave Flume (GWK) of the Forschungszentrum Küste (FZK) in Hannover, Germany and lasted 17 days (15 - 31 October 2013). . A 
detailed description of the excavation of the salt marsh and its installation within the flume, the experimental set-up and the employed instrumentation to measure wave dissipation is given in Möller et al. (2014).

An elevated vegetated test section of $40 \mathrm{~m}$ length was constructed approx. $115 \mathrm{~m}$ from the wave paddle on top of a $1.2 \mathrm{~m}$ high sand base covered by a geotextile layer. This was necessary to ensure sufficient water depth at the wave paddle to generate the desired waves and to allow waves to fully develop before reaching the vegetated test section. At the front and rear end of the vegetated test section a concrete berm, followed by a slope of 1:10 was built to allow the waves to shoal and/or break, as would be the case in a natural shallow water marsh setting (Fig. 2 a). Wave breaking at the 1:6 asphalt slope at the end of the flume minimized wave reflection and active wave absorption of the wave maker.

The vegetated test section consisted of a coherent patchwork of marsh blocks, each with a size of approximately $0.8 \times 1.2 \times 0.3 \mathrm{~m}$. The blocks were vegetated with either Puccinellia, Elymus or the herbaceous forb Atriplex prostrata.

An underwater observation window in the flume wall 6 meters from the start of the vegetated test section allowed the video capture of individual Elymus and Puccinellia movement during the experiment. Four marsh blocks with Puccinellia and four marsh blocks with Elymus were deployed next to each other in front of this window covering an area of $4 \mathrm{~m}^{2}$ respectively. Two 2DElectromagnetic current meters (EMCMs) were positioned on both sides of the underwater observation window approximately $15 \mathrm{~cm}$ above the bed, one in the canopy of Puccinellia and one in the canopy of Elymus (Fig. 2b). During wave tests, the EMCMs recorded wave orbital velocities with a frequency of $100 \mathrm{~Hz}$ and a precision of $\pm 10 \mathrm{~cm} \mathrm{~s}^{-1}$. In the immediate vicinity of the EMCMs, water pressure oscillation was recorded with a PTX1830 pressure wave gauge at the same sampling frequency as the EMCMs $(100 \mathrm{~Hz})$.

The marsh canopy was submerged for $2-3$ days at a time for wave tests. After each two day period of submergence the vegetation was exposed for at least 12 hours to allow plants regular gas exchange. As wave dissipation can be induced through both wave-plant and wave-sediment bottom interactions, a number of tests were conducted with initially intact and then removed (mowed) vegetation (height of remaining plant stems after mowing approx. $2-3 \mathrm{~cm}$ ). This enabled us to quantify the effect of vegetation on the observed wave dissipation. During the course of the experiment the entire vegetated test section was illuminated for the benefit of the plants by a total of 60 lamps (GE 750W 400V PSL or equivalent) mounted along the upper margins of the flume. \#Fig. 2

\#Table 2 


\subsection{Experimental programme}

Eight wave heights $(H ; 1-0.9 m$, seven wave periods $(T ; 1.5-6.2 s)$ and two different water depths ( $\mathrm{h} ; 1 \mathrm{~m}$ and $2 \mathrm{~m}$ ) were simulated to analyze vegetation-wave interactions in canopies of Puccinellia and Elymus (Table 2). For each hydrodynamic condition tested, regular non-breaking waves $(96 \leq \mathrm{N} \leq$ 148) were generated (Table 2).

In order to quantify the wave energy and the drag imparted by wave orbital velocities on the vegetation, as well as the vegetation response to hydrodynamic forcing, we calculated for each test the wave energy flux per meter crest length $(P$, equation 3$)$ and the peak orbital velocity in direction of wave travel $15 \mathrm{~cm}$ above the bed (matching the height at which orbital velocities were recorded within plant canopies) according to linear wave theory ( $U_{\text {predf }}$, equation 5$)$. The Cauchy number ( $C a$, equation 6 ) and the ratio of plant stem height to wave orbital excursion ( $L$, equation 7 ) were calculated according to the formula proposed in Luhar and Nepf (2016). Both $P$ and $U_{\max \text { pred }}$ were determined from wave parameters recorded by the wave gauge set deployed immediately in front of the vegetated test section (Fig. 1a). The first 11 fully developed waves were found to be entirely unaffected by reflection from the flume rear end and were used to determine average wave height ( $H$, from min-max water surface elevations) and period ( $T$, from zero-upcrossing points).

The following formulae were used to calculate $U_{\max \text { pred }}\left(\mathrm{m} \mathrm{s}^{-1}\right), P\left(\mathrm{~kW} \mathrm{~m}^{-1}\right), C a$ and $L$ :

$P=C_{g} E$

in which

$C_{g}=\frac{1}{2}\left[1+\frac{4 \pi h / L_{\text {wave }}}{\sinh \left(\frac{4 \pi h}{L_{\text {wave }}}\right)}\right] \frac{L_{\text {wave }}}{T}$

$E_{\text {wave }}=\frac{1}{8} \rho g H^{2}$

and

$L_{\text {wave }}=\frac{g T^{2}}{2 \pi} \tanh \left(\frac{2 \pi h}{L_{\text {wave }}}\right)$

$U_{\text {peak f pred }}=\frac{\frac{H \pi}{T}}{\operatorname{Sinh}\left(2 \pi \frac{h}{L_{\text {wave }}}\right)}$

$C a=\frac{\rho d U_{\text {peak f pred }}^{2} l^{3}}{E I}$

in which

$I=\frac{\pi d^{4}}{64}$

and

$$
E=\frac{E_{b} I}{I}=\frac{4 s^{3} F}{3 D \pi d^{4}}
$$


315 in which

317 and

$318 \omega=\frac{2 \pi}{T}$

where $C_{g}=$ group wave celerity $\left(\mathrm{m} \mathrm{s}^{-1}\right), E_{\text {wave }}=$ wave energy $\left(\mathrm{J} \mathrm{m}^{-2}\right), H=$ wave height $(\mathrm{m}), T=$ wave period $(\mathrm{s}), L_{\text {wave }}=$ wave length $(\mathrm{m}), h=$ water depth $(\mathrm{m}), A=$ wave orbital excursion $(\mathrm{m}), \omega=$ angular frequency $\left(\mathrm{rad} \mathrm{s}^{-1}\right), \rho=$ water density $\left(1.02 \mathrm{~kg} \mathrm{~m}^{-3}\right), g=$ acceleration by gravity $\left(\mathrm{m}^{3}\left(\mathrm{~kg} \mathrm{~s}^{-1}\right), I=\operatorname{second}\right.$ moment of area $(\mathrm{m}), d=$ plant stem diameter $(\mathrm{m}), I=$ plant stem height $(\mathrm{m}), E_{b}=$ Young's bending modulus $(\mathrm{Pa}) . D=$ vertical deflection of the stem $(\mathrm{m}), F=$ force orthogonal to the plant stem $(\mathrm{N})$ and $s$

$=$ horizontal span of the plant stem $(\mathrm{m})$ in the three-point bending tests used to measure $E_{b}$ (see Rupprecht et al., 2015a).

Conditions with $U_{\text {peakfpred }} \leq 32 \mathrm{~cm} \mathrm{~s}^{-1}$ (corresponding to $P \leq 0.48 \mathrm{~kW} \mathrm{~m}^{-1}$ ) are referred to as 'low orbital velocity'; $42 \leq U_{\text {peakfpred }} \leq 63 \mathrm{~cm} \mathrm{~s}^{-1}$ (corresponding to $0.47 \leq P \leq 1.36 \mathrm{~kW} \mathrm{~m}^{-1}$ ) as 'medium orbital velocity' and $U_{\text {peakf pred }} \geq 74 \mathrm{~kW} \mathrm{~cm} \mathrm{~s}^{-1}$ (corresponding to $0.65 \leq P \leq 3.39 \mathrm{~kW} \mathrm{~m}^{-1}$ ) as 'high orbital velocity' (Table 2, Fig. 4 a). Conditions with values of $U_{\text {peakf pred }}$ and $P$ between these classes were not covered during the experiments.

\subsection{Videography and analysis of plant movement}

Video cameras were installed behind the lateral observation window $6 \mathrm{~m}$ from the front of the vegetated test section (Fig. 2). These cameras recorded the movement of Puccinellia and Elymus at bed level simultaneously to the records of wave orbital velocities in both canopies. Images were continuously acquired at a frequency of $10 \mathrm{~Hz}$.

339 Plant behaviour characteristics for swaying and whip-like movement under wave motion have been reported elsewhere (Bradley and Houser 2009; Manca 2010) and are illustrated in Fig. 2. However, it should be noted that many transitional states exist between these two main types of plant movement. We analyzed plant movement from plant bending angles in the direction of wave travel (hereafter referred to as 'forward' direction), and counter to direction of wave travel (hereafter referred to as 'backward' direction), and the time of maximum stem extension, using 'Kinovea' video analysis software (Kinovea 0.8.15, (c) 2006 - 2011 - Joan Charmant \& Contrib.). The maximum bending angle of stems in, forward and backward direction was measured with the 'angle measurement tool' in 'Kinovea'. The time of maximum stem extension was assessed through frame- 
by-frame tracking of individual plant stems. In 'Kinovea' tracking of objects (here plant stems) is a semi-automatic process. After manually choosing a well distinguishable point on a plant stem, the point location is computed automatically by recording $\mathrm{x}$ (horizontal) and $\mathrm{y}$ (vertical) coordinates in pixels. The tracking process can be interrupted and manually adjusted at any time. In each wave test, we recorded stem movement for an interval of $10-20 \mathrm{~s}$ at the same location in the canopy, thus capturing plant movement under at least four waves. In tests with medium and high hydrodynamic energy, fast canopy movement and high water turbidity, the point location needed to be manually adjusted several times during the tracking process. This may have caused a lower precision of the video analysis in these wave tests. In addition to the analysis of plant movement, the minimum height of the submerged canopy (i.e. canopy height resulting from the maximum bending angle of stems in direction of wave travel) was determined using a measuring tape fixed to the observation window of the flume.

\subsection{Quantification of wave orbital velocities}

Time-series data of orbital velocity under regular non-breaking waves were used to evaluate the effect of canopy movement of Puccinellia and Elymus (observed with the video cameras) on orbital velocities near the sediment bed. The mean peak velocity, both in the direction of wave travel i.e. in 'forward' direction (mean peak forward velocity, $U_{\text {peakf }}$ ) and counter to the direction of wave travel i.e. in 'backward' direction (mean peak backward velocity, $U_{\text {peak }}$ ), were quantified from the horizontal velocity component (component in direction of wave travel) recorded with the EMCMs at a height of $15 \mathrm{~cm}$ above the bed. Tt do so, the peak velocities, both in forward and backward direction, were identified for each wave cycle within the complete time series and then averaged over all waves recorded during the respective test ( $96 \leq \mathrm{N} \leq 148)$.

In shallow water environments, wave shape changes with increasing wave height and wave period, from a symmetric sinusoidal pattern to an asymmetric trochoidal shape characterized by steep wave crests and shallower wave troughs. This change leads to asymmetry in forward and backward orbital velocity. The maximum drag force that can be imparted by the waves on the vegetation canopy under a specific level of wave energy is driven by the stronger orbital velocity in forward direction under the wave crests. For this reason, we focused on $U_{\max }$ recorded within canopies of Puccinellia and Elymus when comparing the responses of the different canopies to wave forcing in terms of movement and their capacities to lessen orbital velocities.

To assess the effect of the presence of Puccinellia and Elymus on orbital velocities as opposed to unvegetated conditions, we compared $U_{\text {peak }}$ measured within both canopies with $U_{\text {peakf }}$ when the canopies were mowed. Differences in orbital velocities between Puccinellia and Elymus, as well as 
between vegetated and mowed conditions, were analyzed for each wave test ( $96 \leq \mathrm{N} \leq 148$ ) with $\mathrm{t}$ tests calculated in R 3.1.0 (R Development Core Team, Vienna, AT).

\subsection{Quantification of physical damage of the vegetation canopy}

To assess the physical damage occurring to the vegetated test section as a whole, all floating biomass was collected by net $(1 \mathrm{~cm}$ mesh) from the water surface at the end of each test, dried and weighed. After the last wave test under vegetated conditions, the whole vegetated test section was mowed to a stem height of $2-3 \mathrm{~cm}$ (see also section 2.2). To quantify the total dry weight of biomass on the test section, the dry weight of the mowed biomass was added to the dry weight of the floating biomass recovered over ithe course of the experiment.

To assess the physical damage to the Elymus canopy, the number of Elymus stems remaining was counted each time when the flume was drained and the plants emergent. The prerequisite of a stem to be counted was that it was not broken, i.e. stems that were folded but not broken were also counted. Stems were counted at 18 quadrats of $10 \times 10 \mathrm{~cm}$ located within a distance of $0.7 \mathrm{~m}$ into the vegetated test section from the flume side wall. The quadrats were distributed in six sets of three replicates from the front to the rear end of the vegetated test section with two of these sets (i.e. six quadrats) located in the front, middle and rear part of the vegetated test section and accessed from a small walkway along one of the flume side walls. The assessment of physical damage to the Elymus canopy as described here was conducted separately from the quantification of stem density for the quantification of biophysical properties of Elymus (see section 2.1).

Physical damage to the Puccinellia canopy was assessed from photographs of the Puccinellia canopy each time the flume was drained at a location close to where the EMCM in the Puccinellia canopy was deployed.

\section{Results}

\subsection{Canopy movement and orbital velocity in Puccinellia and Elymus}

At low orbital velocity both the Puccinellia and Elymus canopy showed a swaying movement under wave motion with similar mean peak forward orbital velocitiy $\left(U_{\text {peak } f}\right)$ and mean peak backward orbital velocity $\left(U_{\text {peak } b}\right)$ (Fig. 4, Table 3$)$.

At medium orbital velocity, larger differences in $U_{\text {peakf }}$ occurred between Puccinellia and Elymus. These differences were associated with the folding of Elymus stems, the transition of swaying to whip-like movement in Puccinellia and long wave periods (4 $-5 \mathrm{~s})$. 
Folding of Elymus stems was first observed at $U_{\text {peakf pred }}=42 \mathrm{~cm} \mathrm{~s}^{-1}$, corresponding to a wave height of $0.4 \mathrm{~m}$ and a wave period of $4.1 \mathrm{~s}$ (Fig. 4, wave test 10 in Table 2). Here the bottom stem parts bent to around $30^{\circ}$, while the upper more flexible stem parts folded over at around $8 \mathrm{~cm}$ above the bed, resulting in a wide bending angle $\left(80-90^{\circ}\right)$ of the Elymus canopy as a whole. In comparison, Puccinellia showed a bending angle of $50^{\circ}$ (Table 3). The more upright posture of the Puccinellia canopy resulted in a greater flow resistance and an $18 \mathrm{~cm} \mathrm{~s}^{-1}$ (37\%) lower orbital velocity under wave forward motion than in Elymus. Time trace analysis of plant stem movement indicated a phase difference of around $20-40^{\circ}$ between canopy movement and wave motion in both the Puccinellia and the Elymus canopy (for an illustration of canopy movement and water motion see Appendix Fig. A.1). At $U_{\text {peak } f \text { pred }}=62 \mathrm{~cm} \mathrm{~s}^{-1}$ the transition from swaying to whip-like movement occurred in Puccinellia (Fig. 4, wave test 12 in Table 2). The wide bending angles in the direction of wave travel (approximately $60^{\circ}$ ) and the long duration of maximum stem extension (approximately $1.5 \mathrm{~s}$ ) allowed the flow to pass unimpeded over the deflected canopy the top of which was at a height of around $9 \mathrm{~cm}$ above the sediment bed for a large part of the wave cycle. In contrast, Elymus showed a swaying movement with folding of stems approx. $6 \mathrm{~cm}$ above the bed (for an illustration of canopy movement and water motion see Appendix Fig. A.2). Whip-like movement of Puccinellia and hence a decrease in flow resistance led to a $26 \mathrm{~cm} \mathrm{~s}^{-1}(54 \%)$ higher orbital velocity under wave forward motion in comparison to Elymus (Table 2).

At high orbital velocity both Puccinellia and Elymus exhibited a whip-like movement (Table 3). $U_{\text {peakf }}$ in Puccinellia exceeded $U_{\text {peakf }}$ in Elymus by $5-18 \mathrm{~cm} \mathrm{~s}^{-1}$ (6-22\%; Fig. 4, wave test 14 in Table 2). During wave forward motion, both canopies were in a flattened 'shielding posture' (canopy height above the bed $=7 \mathrm{~cm}$ in Puccinellia, $5 \mathrm{~cm}$ in Elymus) and presumably provided low flow resistance. In both Puccinellia and Elymus a phase difference occurred between canopy movement and wave motion. In Elymus the phase difference was much larger (around $90^{\circ}$ ) than in Puccinellia (around $30-$ $40^{\circ}$, for an illustration of canopy movement and water motion see Appendix Fig. A.3).

The Cauchy number Ca ranged in Puccinellia from 0.3 - 671 and in Elymus from 0.4 - 994 (Fig. 4, Table 4). Small differences ( $\leq 39$ ) of $\mathrm{Ca}$ in both canopies at low orbital velocity reflect their similar response to hydrodynamic forcing in terms of canopy movement. From medium orbital velocity onwards differences of $\mathrm{Ca}$ in Puccinellia and Elymus increased ( $68 \leq \mathrm{X} \leq 322$ ) (Table 4) with higher values of $\mathrm{Ca}$ in Elymus compared to Puccinellia. The ratio of canopy height to wave orbital excursion $L$ ranged in the low-growing Puccinellia from 42.9-0.3 and in the tall Elymus from 166.9-1.2. The onset of whip-like movement was at $L=0.6$ in Puccinellia and at $L=1.8$ in the Elymus canopy. 


\subsection{Orbital velocity in Puccinellia and Elymus under vegetated and mowed} conditions

At low orbital velocity, presence of the Puccinellia canopy caused a small reduction $\left(4-6 \mathrm{~cm} \mathrm{~s}^{-1}\right.$, $(-18$ to $-19 \%))$ and presence of the Elymus canopy a small increase in of $U_{\text {peakf } f}\left(2-6 \mathrm{~cm} \mathrm{~s}^{-1}(+13\right.$ to $+21 \%)$ ). With EMCMs measuring orbital velocity at a precision of $\pm 10 \mathrm{~cm} \mathrm{~s}^{-1}$ (see Methods section 2.2) these small differences in $U_{\text {peakf }}$ under vegetated and mowed conditions suggest a minor effect of vegetation presence on orbital velocity.

At medium orbital velocity, the effect of Puccinellia and Elymus on $U_{\text {peak } f}$ varied with water depth and wave period. Under a water depth of $2 \mathrm{~m}$ and long wave periods (4.1 s), when both Puccinellia and Elymus exhibited a swaying movement, we found Puccinellia to reduce $U_{\text {peakf }}$ by $16 \mathrm{~cm} \mathrm{~s}^{-1}$ (35\%). The Elymus canopy, where the folding of stems occurred, had no significant effect on $U_{\text {peakf }}$ (Fig. 5 , Table 4). Under a water depths of $1 \mathrm{~m}$ and short wave periods (2.9 s), Puccinellia caused an increase of $U_{\text {peakf }}$ of $13 \mathrm{~cm} \mathrm{~s}^{-1}(+20 \%)$ and Elymus a decrease by $7 \mathrm{~cm} \mathrm{~s}^{-1}(-13 \%)$. This change in the effect of Puccinellia and Elymus on $U_{\text {peak }}$ occurred simultaneously with the transition from swaying to whiplike canopy movement in Puccinellia (Fig. 4, 5).

Finally at high orbital velocity, when both canopies exhibited a whip-like movement, Puccinellia and Elymus caused an increase of $U_{\text {peakf }}$ by $5 \mathrm{~cm} \mathrm{~s}^{-1}(+13 \%)$ and $7 \mathrm{~cm} \mathrm{~s}^{-1}(+13 \%)$ respectively (Fig. 5 , Table 4).

Differences in $U_{\text {peakf }}$ when the vegetation was mowed and the predicted peak forward velocity $U_{\text {peak f pred }}$ as theoretical value of orbital velocity over a flat, surface without vegetation ranged between 0.5 and $6.6 \mathrm{~cm}-1$ (Table 4). This suggests $U_{\text {peakf pred }}$ to be a good proxy for orbital velocities near the sediment bed in absence of vegetation.

\subsection{Physical damage to the vegetation canopy}

Cumulatively around $45 \%$ of the total $98 \mathrm{~kg}$ of above ground biomass was lost under the wave forces applied in the experiment (Fig. 6). Photo documentation of Puccinellia and records of stem density in Elymus during the course of the experiment revealed that the two canopies differed in their susceptibility to plant stem breakage under increasing orbital velocities. The Puccinellia canopy with its high stem flexibility withstood the hydrodynamic forces without substantial damage (Fig. 7) 
sediment surface occurred from medium orbital velocities onwards $\left(U_{\text {peak }} f\right.$ pred $\geq 42 \mathrm{~cm} \mathrm{~s} \mathrm{~s}^{-1}$ corresponding to wave heights $\geq 0.4 \mathrm{~m}$ ). In total, a loss of approximately $80 \%$ of Elymus stems was observed on the $1810 \times 10 \mathrm{~cm}$ quadrats distributed over the length of the vegetated test section (Fig. 6). No significant difference was found between stem loss in quadrats in the front, middle and rear part of the vegetated test section (kruskal-wallis-test; chi-squared $=0.34, d f=2, p=0.84$ ).

Wave tests with $U_{\text {peakfpred }}$ of $30-76 \mathrm{~cm} \mathrm{~s}^{-1}$ and wave heights of $0.4-0.7 \mathrm{~m}$ on day 7 and day 8 of the experiment resulted in folding and breakage of $45 \%$ of Elymus stems (Fig. 6). This loss of Elymus stems occurred simultaneously with the largest share of biomass loss as averaged over the whole test section. Another $35 \%$ of Elymus stems were lost during wave tests from day 10 to 11 , with wave heights up to $0.9 \mathrm{~m}$ and $U_{\text {peakf pred }}$ up to $90 \mathrm{~cm} \mathrm{~s}^{-1}$.

\#Fig. 6

\#Fig. 7

\section{Discussion}

Understanding the mechanisms of vegetation-induced wave dissipation on the one hand, and vulnerability of the marshes to vegetation damage and erosion on the other hand, is of crucial importance to successfully predict and incorporate the wave dissipation capacity of salt marshes into coastal defence schemes (Howes et al., 2010; Leonardi et al., 2016; Luhar and Nepf 2016; Möller et al., 2014). The near-field scale experimental results presented in this paper provide clear evidence for differences in the interaction between each of two common salt marsh species, Puccinellia and Elymus, and forward orbital velocity near the bed as well as for differences in the susceptibility of both canopies to physical damage under rising orbital velocities and wave energy flux. Our findings provide insights in how the contribution of vegetation to wave dissipation and surface erosion protection varies with plant biophysical characteristics and hydrodynamic conditions and have implications for numerical modelling of the marsh wave dissipation capacity and salt marsh management schemes.

\subsection{Effect of Puccinellia and Elymus canopies on near-bed orbital velocities}

\section{Low orbital velocity}

At low orbital velocities $\left(U_{\text {peakf pred }} \leq 32 \mathrm{~cm} \mathrm{~s}^{-1}\right)$ and $C a$ values $\leq 120$, our results suggest a minor effect of vegetation and its biophysical characteristics on near-bed orbital velocities and bed shear stress. Such findings were also reported by Neumeier and Amos (2006b) who measured a reduction of orbital velocity by $10-20 \%$ at low orbital velocities and wave energy ( $h \leq 0.9 m, H \leq 0.09 m$ ) in Spartina anglica salt marshes of Eastern England, assuming this reduction to be of minor importance 
for the deposition and erosion of sediments. Wave damping was also observed to be lower for waves of smaller height than for more energetic waves in Maza et al.'s (2015) laboratory experiment, in which Spartina anglica and Puccinellia maritima species were subjected to waves of between 0.12 and $0.2 \mathrm{~m}$ height in $<1.0 \mathrm{~m}$ water depth.

\section{Medium orbital velocity}

At medium orbital velocities $\left(U_{\text {peakfpred }} 42 \leq U_{\text {peakfpred }} \leq 63 \mathrm{~cm} \mathrm{~s}^{-1}\right.$ ) and $141 \leq C a \leq 473$ we found larger differences in the effect of Puccinellia and Elymus on orbital velocity, caused by a different degree of 'canopy flattening' and different susceptibility to stem folding between the two canopies. Differences in the response of Puccinellia and Elymus to medium orbital velocities are also reflected by larger differences in values of $\mathrm{Ca}$ between both canopies, compared to low orbital velocities. Lower values of $\mathrm{Ca}$ in Puccinellia in comparison to Elymus imply a greater ability of Puccinellia to reorientation after bending and hence a higher flow resistance. This holds true under a water depth of $2 \mathrm{~m}$ and long wave periods ( $4.1 \mathrm{~s}$ ), when stem folding was observed for the first time in Elymus. Here we found no significant effect of Elymus on orbital velocity. By contrast, Puccinellia caused a considerable decline in orbital velocity $(-35 \%)$, a decrease that may enhance sediment deposition and decrease bed shear stress. In the field, reduction of orbital velocity by Puccinellia could even be higher given the lower stem flexibility of Puccinellia in the field compared to the flume (Table 1). In all of the other tests at medium orbital velocity however, higher orbital velocity in Puccinellia suggests a lower flow resistance compared to Elymus. This is presumably because the onset of whiplike movement occurred in Puccinellia at lower (medium) orbital velocity than in Elymus, an effect that could not be captured by the calculation of $\mathrm{Ca}$.

The transition from swaying to whip-like movement occurred in Puccinellia at a value of $C a=319$ and $L=0.6$ and hence at a greater wave orbital excursion and higher orbital velocities as assumed for flexible aquatic vegetation, where properties of whip-like movement are postulated to only start to occur at $L$ values of $=1$ (Luhar and Nepf, 2016). In Elymus the transition to whip-like movement occurred at $C a=664$ and $L=1.8$, suggesting that folding of stems may favour the onset of whip-like movement.

\section{High orbital velocity}

At high orbital velocities $\left(U_{\text {peakfpred }} \geq 74 \mathrm{~cm} \mathrm{~s}^{-1}\right)$ and $449 \leq C a \leq 994$ both Puccinellia and Elymus caused an increase of orbital velocity compared to mowed conditions and exhibited a whip-like movement. The reconfiguration of canopies to a flattened 'shielding' posture, close to the soil surface for a large part of the wave cycle, can be expected to protect the bed from erosive processes. However, high orbital velocities above the canopy may reduce the chance of sediment particles settling on the bed, thus leading to a passive protective role of the canopy rather than an active sediment-enhancing role (Neumeier and Ciavola 2004; Peralta et al., 2008). 

canopy. characteristic for storm surges. The dependence of wave-vegetation interactions on wave period has been observed in many flume, field and modelling studies (Bradley and Houser 2009; Jadhav et al., 2013; Lowe et al., 2007; Mullarney and Henderson 2010; Paul and Amos 2011; Maza et al., 2015). It has been suggested that depending on the biophysical properties of the plant species, canopies can act as a band-pass filter preferentially damping short or long-period waves while intermediate frequencies pass more easily (Mullarney and Henderson 2010). Moreover, it is to be expected that biophysical plant characteristics impact most on the vegetation-wave interactions at long-period waves as those tend to have larger velocities throughout the water column than short period waves (Anderson et al., 2011).

Our results show that in contrast to medium orbital velocities and long wave periods, where Puccinellia and Elymus differed in the degree of canopy flattening and ability to reduce orbital velocity, at high orbital velocities and a wave period of $5.1 \mathrm{~s}$, both Puccinellia and Elymus took a flattened posture and caused an increase in orbital velocity compared to mowed conditions. However, both canopies showed differences in their capacity to provide resistance due to relative motion between plants and water (i.e. the phase difference between canopy and water movement). The greater phase difference and lower values of mean peak forward orbital velocity suggest a higher resistance, and hence greater potential for flow and wave dissipation, in the presence of an Elymus

In summary, our results imply a species-specific vegetation control on near-bed orbital velocities, sediment transport and deposition at medium orbital velocities, at least at spatial and temporal scales on which other controls, such as sediment supply and incident hydrodynamic conditions can be assumed to be relatively invariant (French and Spencer 1993). These insights add an additional dimension to existing laboratory studies with real vegetation but relatively low energy conditions (depths $\leq 1 \mathrm{~m} ; \mathrm{H} \leq 0.2 \mathrm{~m}$ ) in which vegetation density may exert a greater control than species flexibility on wave dissipation (Maza et al., 2015). Our results suggest, however, that the type of vegetation movement which is linked to plant flexibility, remains critical in determining plant-wave interactions and the effects of this interaction on orbital velocity.

583 
Throughout the experiment the salt marsh vegetation canopy as a whole experienced moderate physical damage and the sediment surface withstood large wave forces without substantial erosion (Möller et al., 2014; Spencer et al., 2016). This suggests a high resilience of sediment surfaces under a vegetated salt marsh canopy to storm surge conditions. With the root mat remaining intact, damage to the vegetation canopy reported in this paper can be considered to be of a temporary nature meaning that recovery may be expected during the next growing season. This is especially valid for plant species that can reproduce by clonal growth, a characteristic of both the grass species investigated in this study. However, recovery is unlikely to occur between storms clustered over a short interval in the order of weeks, particularly likely in northern winter months when most storm surges occur (Cusack, 2016). The latter may have implications for the coastal protection value of the marsh for reoccurring storms or storms of longer duration (several days). Indeed a recent global analysis on salt marsh erosion and wave measurements by Leonardi et al., (2016) revealed that most of salt marsh deterioration is caused by moderate storms of a monthly frequency while violent storms and hurricanes occurring at a decadal timescale contribute less than $1 \%$ to long-term salt marsh erosion rates. Moreover interior marsh surfaces as investigated in our study have been shown to be much less responsive to wave action than fringing marshes (Fagherazzi 2013; Fagherazzi et al., 2013; Feagin et al., 2009). Further studies are needed to investigate the links between vegetation and root system characteristics, organic matter dynamics and the erosion stability of marsh edges.

The canopies of Puccinellia and Elymus differed in their susceptibility to stem folding and breakage under increasing orbital velocities and wave energy flux. The very low amount of physical damage occurring to Puccinellia can be attributed to its very flexible stems allowing reconfiguration of the canopy to a flat shielding posture close to the bed under high orbital velocities (cf. observations in Bouma et al. 2010; Bouma et al. 2013). A similar strategy to survive under high flow and wave-induced velocities by avoiding high drag forces through reconfiguration is also known for flexible sea grasses (Infantes et al., 2011; Peralta et al., 2008) and freshwater macrophytes (O'Hare et al., 2007; Puijalon et al., 2011; Robionek et al., 2015).

Providing low flow resistance, the direct contribution to hydrodynamic energy dissipation by very flexible plants is small. At the water-sediment interface, however, the flattened plant canopies under high velocities, reduce friction forces and contribute, along with plant roots and sediment organic matter content, to the stabilization of sediment surface and long-term marsh stability (Neumeier and Ciavola 2004; Peralta et al., 2008).

In contrast to Puccinellia, the less flexible and tall Elymus canopy experienced folding and subsequent breakage of stems from medium orbital velocities and above. Turbulence around stumps remaining on the marsh surface after stem breakage can increase bed shear stress and bed erosion through local scour. This is confirmed by a study of Spencer et al., (2016) who investigated soil 
surface elevation change in the framework of the present flume experiment. They found surfaces covered by the flattened canopy of Puccinellia experienced a lower and less variable elevation loss than those characterized by Elymus. The susceptibility of Elymus stems to breakage in the field under high orbital velocity may be even higher than that observed in this experiment. On the other hand, the cumulative effects of wave forces on the Elymus canopy could also imply that the stem loss experienced at medium orbital velocities enhanced the susceptibility of Elymus to folding and breakage at high orbital velocities compared to similar velocities under field conditions.

Physical damage and hence a decline in flow resistance of Elymus from medium orbital velocities onwards observed in this study coincided with a leveling-off in the wave-dissipation capacity of the vegetated test section as a whole (Möller et al., 2014). With Elymus covering the largest part of the vegetated test section (around 70\%) in this flume experiment, this result suggests that changes in vegetation-wave interactions may exert an important control on wave dissipation by salt marshes under increasing orbital velocities and wave energy flux.

\section{Conclusions}

In this paper, we investigated salt marsh vegetation-wave interactions over a wide range of wave conditions, from low to high wave orbital velocities and wave energy flux and in a near-field scale flume experiment. The results of our study show that canopy height and flexibility, as well as incident wave heights, wave periods and water depth, play an important role in the way vegetation interacts with waves. Furthermore, for the conditions and plant species tested here, the ability of vegetation to reduce near-bed wave orbital velocities and vegetation susceptibility to breakage varied with plant biophysical characteristics from an orbital velocity of $42 \mathrm{~cm} \mathrm{~s}^{-1}$ onwards. To profit from the benefits that plant species differing in biophysical characteristics provide in terms of wave dissipation and surface erosion protection under storm surge conditions, management schemes should aim for the maintenance of plant species diversity. Given the large variability in biophysical properties between salt marsh plant species (Feagin et al., 2011; Rupprecht et al., 2015a) it is recommended that further studies focus on the behavior of a wider range of salt marsh canopies, ideally under the full range of water depth and wave conditions that can be expected to occur on coasts periodically impacted by severe storms. While Elymus athericus and Puccinellia maritima are common species in the NW European region, the occurrence of mono-specific stands of Spartina anglica and Spartina alterniflora along the coastline of the United States and China, as well as NW Europe, calls for a separate investigation of vegetation-wave interactions in these types of marshes. Such studies are needed because these species often feature in coastal wetland creation schemes (Borsje et al., 2011; Kabat et al., 2009; Temmerman et al., 2013). Knowledge on species-specific thresholds of orbital velocities and wave energy flux marking changes in flow resistance, as well as future studies 
656 providing such thresholds for mixed canopies, might then inform modelling studies generating 657 predictions of marsh stability and resilience over longer time-scales, feeding into the growing body of 658 knowledge that will ultimately allow salt marshes to be fully and effectively incorporated into coastal 659 protection schemes.

660

\section{Acknowledgements}

662 We thank all of the staff at the Großer Wellenkanal as well as B. Evans, J. Tempest, K. Milonidis and C. 663 Edwards, Cambridge University, and D. Schulze, Hamburg University, for their invaluable logistical 664 assistance, Fitzwilliam College for supporting the research time of I.M., and C. Rolfe, Cambridge 665 University, for the soil analysis and Deltares for the support by the Strategic Research Programme on 666 dikes, levees and dams. M.P. acknowledges funding by the German Science Foundation (grant no. PA 667 2547/1-1). The work described in this publication was supported by the European Community's $7^{\text {th }}$ 668 Framework Programme through the grant to the budget of the Integrating Activity HYDRALAB IV, 669 Contract no. 261529 and by a grant from The Isaac Newton Trust, Trinity College, Cambridge.

670 


\section{References}

Aberle, J.; Jarvela, J. Flow resistance of emergent rigid and flexible floodplain vegetation. J Hydraul Res. 51:33-45; 2013

Anderson, M.E.; Smith, J.M. Wave attenuation by flexible, idealized salt marsh vegetation. Coastal Engineering. 83:82-92; 2014

Anderson, M.E.; Smith McKee, J.; Keyle McKay, S. Wave Dissipation by Vegetation.Coastal and Hydraulics Engineering Technical Note ERDC/CHL CHETN-I-82, Vicksburg MS, U.S. Army Engineer Research and Development Center; 2011

Augustin, L.N.; Irish, J.L.; Lynett, P. Laboratory and numerical studies of wave damping by emergent and near-emergent wetland vegetation. Coastal Engineering. 56:332-340; 2009

Bockelmann, A.C.; Neuhaus, R. Competitive exclusion of Elymus athericus from a high-stress habitat in a European salt marsh. Journal of Ecology. 87:503-513; 1999

Borsje, B.W.; van Wesenbeeck, B.K.; Dekker, F.; Paalvast, P.; Bouma, T.J.; van Katwijk, M.M.; de Vries, M.B. How ecological engineering can serve in coastal protection. Ecological Engineering. 37:113-122; 2010

Bouma, T.J.; De Vries, M.B.; Herman, P.M.J. Comparing ecosystem engineering efficiency of two plant species with contrasting growth strategies. Ecology. 91:2696-2704; 2010

Bouma, T.J.; De Vries, M.B.; Low, E.; Peralta, G.; Tanczos, C.; Van de Koppel, J.; Herman, P.M.J. Tradeoffs related to ecosystem engineering: A case study on stiffness of emerging macrophytes. Ecology. 86:2187-2199; 2005

Bouma, T.J.; van Belzen, J.; Balke, T.; Zhu, Z.; Airoldi, L.; Blight, A.J.; Davies, A.J.; Galvan, C.; Hawkins, S.J.; Hoggart, S.P.G.; Lara, J.L.; Losada, I.J.; Maza, M.; Ondiviela, B.; Skov, M.W.; Strain, E.M.; Thompson, R.C.; Yang, S.; Zanuttigh, B.; Zhang, L.; Herman, P.M.J. Identifying knowledge gaps hampering application of intertidal habitats in coastal protection: Opportunities \& steps to take. Coastal Engineering. 87:147-157; 2014

Bradley, K.; Houser, C. Relative velocity of seagrass blades: Implications for wave attenuation in lowenergy environments. Journal of Geophysical Research-Earth Surface. 114; 2009

Cahoon, D.R. A review of major storm impacts on coastal wetland elevations. Estuaries and Coasts. 29:889-898; 2006

Chen, S.-N.; Sanford, L.P.; Koch, E.W.; Shi, F.; North, E.W. A nearshore model to investigate the effects of seagrass bed geometry on wave attenuation and suspended sediment transport. Estuaries and Coasts. 30:296-310; 2007

Dijkstra, J.T.; Uittenbogaard, R.E. Modeling the interaction between flow and highly flexible aquatic vegetation. Water Resources Research. 46; 2010

Duarte, C.M.; Losada, I.J.; Hendriks, I.E.; Mazarrasa, I.; Marbà, N. The role of coastal plant communities for climate change mitigation and adaptation. Nature Climate Change. 3:961968; 2013

Fagherazzi, S. The ephemeral life of a salt marsh. Geology. 41:943-944; 2013

Fagherazzi, S.; Mariotti, G.; Wiberg, P.L.; McGlathery, K.J. Marsh collapse does not require sea level rise. Oceanography. 26:70-77; 2013

Feagin, R.A.; Irish, J.L.; Möller, I.; Williams, A.M.; Colon-Rivera, R.J.; Mousavi, M.E. Short communication: Engineering properties of wetland plants with application to wave attenuation. Coastal Engineering. 58:251-255; 2011

Feagin, R.A.; Lozada-Bernard, S.M.; Ravens, T.M.; Moeller, I.; Yeager, K.M.; Baird, A.H. Does vegetation prevent wave erosion of salt marsh edges? Proceedings Of The National Academy Of Sciences Of The United States Of America. 106:10109-10113; 2009

Fonseca, M.S.; Cahalan, J.A. A preliminary evaluation of wave attenuation by four species of seagrass. Estuarine Coastal and Shelf Science. 35:565-576; 1992

French, J.R.; Spencer, T. Dynamics of sedimentation in a tide-dominated backbarrier salt-marsh, Norfolk, UK. Marine Geology. 110:315-331; 1993 
Gaylord, B.; Denny, M.W. Flow and flexibility - I. Effects of size, shape and stiffness in determining wave forces on the stipitate kelps Eisenia arborea and Pterygophora californica. Journal of Experimental Biology. 200:3141-3164; 1997

Gedan, K.B.; Kirwan, M.L.; Wolanski, E.; Barbier, E.B.; Silliman, B.R. The present and future role of coastal wetland vegetation in protecting shorelines: answering recent challenges to the paradigm. Climatic Change. 106:7-29; 2011

Heuner, M.; Silinski, A.; Schoelynck, J.; Bouma, T.J.; Puijalon, S.; Troch, P.; Fuchs, E.; Schroder, B.; Schroder, U.; Meire, P.; Temmerman, S. Ecosystem Engineering by Plants on Wave-Exposed Intertidal Flats Is Governed by Relationships between Effect and Response Traits. Plos One. $10 ; 2015$

Howes, N.C.; FitzGerald, D.M.; Hughes, Z.J.; Georgiou, I.Y.; Kulp, M.A.; Miner, M.D.; Smith, J.M.; Barras, J.A. Hurricane-induced failure of low salinity wetlands. Proceedings of the National Academy of Sciences of the United States of America. 107:14014-14019; 2010

Infantes, E.; Orfila, A.; Bouma, T.J.; Simarro, G.; Terrados, J. Posidonia oceanica and Cymodocea nodosa seedling tolerance to wave exposure. Limnology and Oceanography. 56:2223-2232; 2011

Jadhav, R.S.; Chen, Q.; Smith, J.M. Spectral distribution of wave energy dissipation by salt marsh vegetation. Coastal Engineering. 77:99-107; 2013

Kabat, P.; Fresco, L.O.; Stive, M.J.F.; Veerman, C.P.; van Alphen, J.S.L.J.; Parmet, B.W.A.H.; Hazeleger, W.; Katsman, C.A. Dutch coasts in transition. Nature Geoscience. 2:450-452; 2009

Kirwan, M.L.; Temmerman, S.; Skeehan, E.E.; Guntenspergen, G.R.; Fagherazzi, S. Overestimation of marsh vulnerability to sea level rise. Nature Climate Change. 6:253-260; 2016

Koch, E.W.; Barbier, E.B.; Silliman, B.R.; Reed, D.J.; Perillo, G.M.E.; Hacker, S.D.; Granek, E.F.; Primavera, J.H.; Muthiga, N.; Polasky, S.; Halpern, B.S.; Kennedy, C.J.; Kappel, C.V.; Wolanski, E. Non-linearity in ecosystem services: temporal and spatial variability in coastal protection. Frontiers in Ecology and the Environment. 7:29-37; 2009

Leonard, L.A.; Croft, A.L. The effect of standing biomass on flow velocity and turbulence in Spartina alterniflora canopies. Estuarine Coastal and Shelf Science. 69:325-336; 2006

Leonard, L.A.; Reed, D.J. Hydrodynamics and Sediment Transport Through Tidal Marsh Canopies. Journal of Coastal Research:459-469; 2002

Leonardi, N.; Ganju, N.K.; Fagherazzi, S. A linear relationship between wave power and erosion determines salt-marsh resilience to violent storms and hurricanes. Proceedings of the National Academy of Sciences of the United States of America. 113:64-68; 2016

Lowe, R.J.; Falter, J.L.; Koseff, J.R.; Monismith, S.G.; Atkinson, M.J. Spectral wave flow attenuation within submerged canopies: Implications for wave energy dissipation. J Geophys Res-Oceans. $112 ; 2007$

Luhar, M.; Nepf, H.M. Flow-induced reconfiguration of buoyant and flexible aquatic vegetation. Limnology and Oceanography. 56:2003-2017; 2011

Luhar, M.; Nepf, H.M. Wave-induced dynamics of flexible blades. Journal of Fluids and Structures. $61: 20-41 ; 2016$

Manca, E. Effects of Posidonia oceanica seagrass on nearshore waves and wave-induced flows. PhD thesis, University of Southampton. Southampton, UK.: University of Southampton; 2010

McLeod, E.; Chmura, G.L.; Bouillon, S.; Salm, R.; Bjork, M.; Duarte, C.M.; Lovelock, C.E.; Schlesinger, W.H.; Silliman, B.R. A blueprint for blue carbon: toward an improved understanding of the role of vegetated coastal habitats in sequestering $\mathrm{CO} 2$. Frontiers in Ecology and the Environment. 9:552-560; 2011

Mendez, F.J.; Losada, I.J. An empirical model to estimate the propagation of random breaking and nonbreaking waves over vegetation fields. Coastal Engineering. 51:103-118; 2004

Möller, I.; Kudella, M.; Rupprecht, F.; Spencer, T.; Paul, M.; van Wesenbeeck, B.K.; Wolters, G.; Jensen, K.; Bouma, T.J.; Miranda-Lange, M.; Schimmels, S. Wave attenuation over coastal salt marshes under storm surge conditions. Nature Geoscience. 7:727-731; 2014 
Möller, I.; Spencer, T.; French, J.R. Wind Wave Attenuation over Saltmarsh Surfaces: Preliminary Results from Norfolk, England. Journal of Coastal Research. 12:1009-1016; 1997

Möller, I.; Spencer, T.; French, J.R.; Leggett, D.J.; Dixon, M. Wave transformation over salt marshes: A field and numerical modelling study from north Norfolk, England. Estuarine, Coastal and Shelf Science. 49:411-426; 1999

Mullarney, J.C.; Henderson, S.M. Wave-forced motion of submerged single-stem vegetation. J Geophys Res-Oceans. 115:C12061. doi:12010.11029/12010JC006448; 2010

Neumeier, U.; Amos, C.L. The influence of vegetation on turbulence and flow velocities in European salt-marshes. Sedimentology. 53:259-277; 2006a

Neumeier, U.; Amos, C.L. Turbulence reduction by the canopy of coastal Spartina salt-marshes. Journal of Coastal Research. SI39:433-439; 2006b

Neumeier, U.; Ciavola, P. Flow resistance and associated sedimentary processes in a Spartina maritima salt-marsh. Journal of Coastal Research. 20:435-447; 2004

O'Hare, M.T.; Hutchinson, K.A.; Clarke, R.T. The drag and reconfiguration experienced by five macrophytes from a lowland river. Aquatic Botany. 86:253-259; 2007

Paul, M.; Amos, C.L. Spatial and seasonal variation in wave attenuation over Zostera noltii. J Geophys Res-Oceans. 116:C08019; 2011

Paul, M.; Bouma, T.J.; Amos, C.L. Wave attenuation by submerged vegetation: combining the effect of organism traits and tidal current. Marine Ecology Progress Series. 444:31-41; 2012

Paul, M.; Rupprecht, F.; Möller, I.; Bouma, T.J.; Spencer, T.; Kudella, M.; Wolters, G.; van Wesenbeeck, B.K.; Jensen, K.; Miranda-Lange, M.; Schimmels, S. Plant stiffness and biomass as drivers for drag forces under extreme wave loading: A flume study on mimics. Coastal Engineering. 117:70-78; 2016

Peralta, G.; van Duren, L.A.; Morris, E.P.; Bouma, T.J. Consequences of shoot density and stiffness for ecosystem engineering by benthic macrophytes in flow dominated areas: a hydrodynamic flume study. Marine Ecology Progress Series. 368:103-115; 2008

Puijalon, S.; Bouma, T.J.; Douady, C.J.; van Groenendael, J.; Anten, N.P.R.; Martel, E.; Bornette, G. Plant resistance to mechanical stress: evidence of an avoidance-tolerance trade-off. New Phytologist. 191:1141-1149; 2011

Riffe, K.C.; Henderson, S.M.; Mullarney, J.C. Wave dissipation by flexible vegetation. Geophysical Research Letters. 38; 2011

Robionek, A.; Banas, K.; Chmara, R.; Szmeja, J. The avoidance strategy of environmental constraints by an aquatic plant Potamogeton alpinus in running waters. Ecol Evol. 5:3327-3337; 2015

Rupprecht, F.; Möller, I.; Evans, B.; Spencer, T.; Jensen, K. Biophysical properties of salt marsh canopies - Quantifying plant stem flexibility and above ground biomass Coastal Engineering DOI: 10.1016/j.coastaleng.2015.1003.1009; 2015a

Rupprecht, F.; Wanner, A.; Stock, M.; Jensen, K. Succession in salt marshes - large-scale and longterm patterns after abandonment of grazing and drainage. Applied Vegetation Science. 18:86-98; 2015b

Sand-Jensen, K. Drag and reconfiguration of freshwater macrophytes. Freshwater Biology. 48:271$283 ; 2003$

Schuerch, M.; Vafeidis, A.; Slawig, T.; Temmerman, S. Modeling the influence of changing storm patterns on the ability of a salt marsh to keep pace with sea level rise. Journal of Geophysical Research-Earth Surface. 118:84-96; 2013

Silinski, A.; Heuner, M.; Schoelynck, J.; Puijalon, S.; Schroder, U.; Fuchs, E.; Troch, P.; Bouma, T.J.; Meire, P.; Temmerman, S. Effects of Wind Waves versus Ship Waves on Tidal Marsh Plants: A Flume Study on Different Life Stages of Scirpus maritimus. Plos One. 10:16; 2015

Spencer, T.; Moller, I.; Rupprecht, F.; Bouma, T.J.; van Wesenbeeck, B.K.; Kudella, M.; Paul, M.; Jensen, K.; Wolters, G.; Miranda-Lange, M.; Schimmels, S. Salt marsh surface survives true-toscale simulated storm surges. Earth Surface Processes and Landforms. 41:543-552; 2016

Stewart, H.L. Hydrodynamic consequences of flexural stiffness and buoyancy for seaweeds: a study using physical models. Journal of Experimental Biology. 209:2170-2181; 2006 
Stumpf, R.P. The process of sedimentation on the surface of a salt-marsh. Estuarine Coastal and Shelf Science. 17:495-508; 1983

Temmerman, S.; Bouma, T.J.; Govers, G.; Wang, Z.B.; De Vries, M.B.; Herman, P.M.J. Impact of vegetation on flow routing and sedimentation patterns: Three-dimensional modeling for a tidal marsh. Journal of Geophysical Research-Earth Surface. 110:F04019; 2005

Temmerman, S.; Meire, P.; Bouma, T.J.; Herman, P.M.J.; Ysebaert, T.; De Vriend, H.J. Ecosystembased coastal defence in the face of global change. Nature. 504:79-83; 2013

Turner, R.E.; Baustian, J.J.; Swenson, E.M.; Spicer, J.S. Wetland sedimentation from Hurricanes Katrina and Rita. Science. 314:449-452; 2006

Valéry, L.; Bouchard, V.; Lefeuvre, J.C. Impact of the invasive native species Elymus athericus on carbon pools in a salt marsh. Wetlands. 24:268-276; 2004

Veeneklaas, R.M.; Dijkema, K.S.; Hecker, N.; Bakker, J.P. Spatio-temporal dynamics of the invasive plant species Elytrigia atherica on natural salt marshes. Applied Vegetation Science. 16:205$216 ; 2013$

Yang, S.L.; Shi, B.W.; Bouma, T.J.; Ysebaert, T.; Luo, X.X. Wave attenuation at a salt marsh margin: A case study of an exposed coast on the Yangtze Estuary. Estuaries and Coasts. 35:169-182; 2012 


\section{$845 \quad$ Figure 1}

846

847

(a)

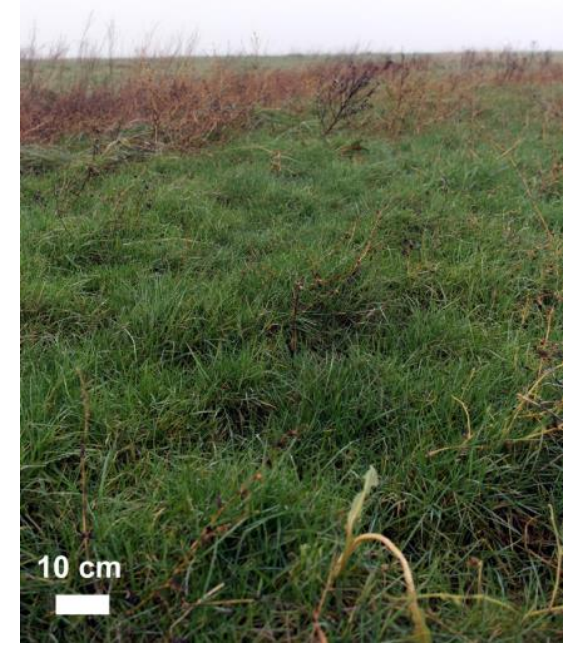

859

860

861

862

863

864

865

866

867

868

869

870

871

872 North Sea Coast in Eastern Frisia, Germany.

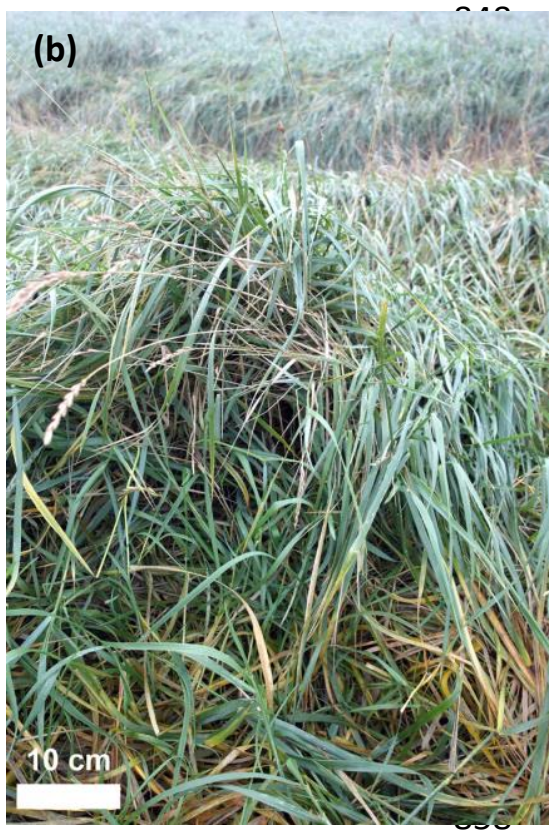

Fig. 1: Canopies of the salt marsh grasses (a) Puccinellia maritima and (b) Elymus athericus at the 
874

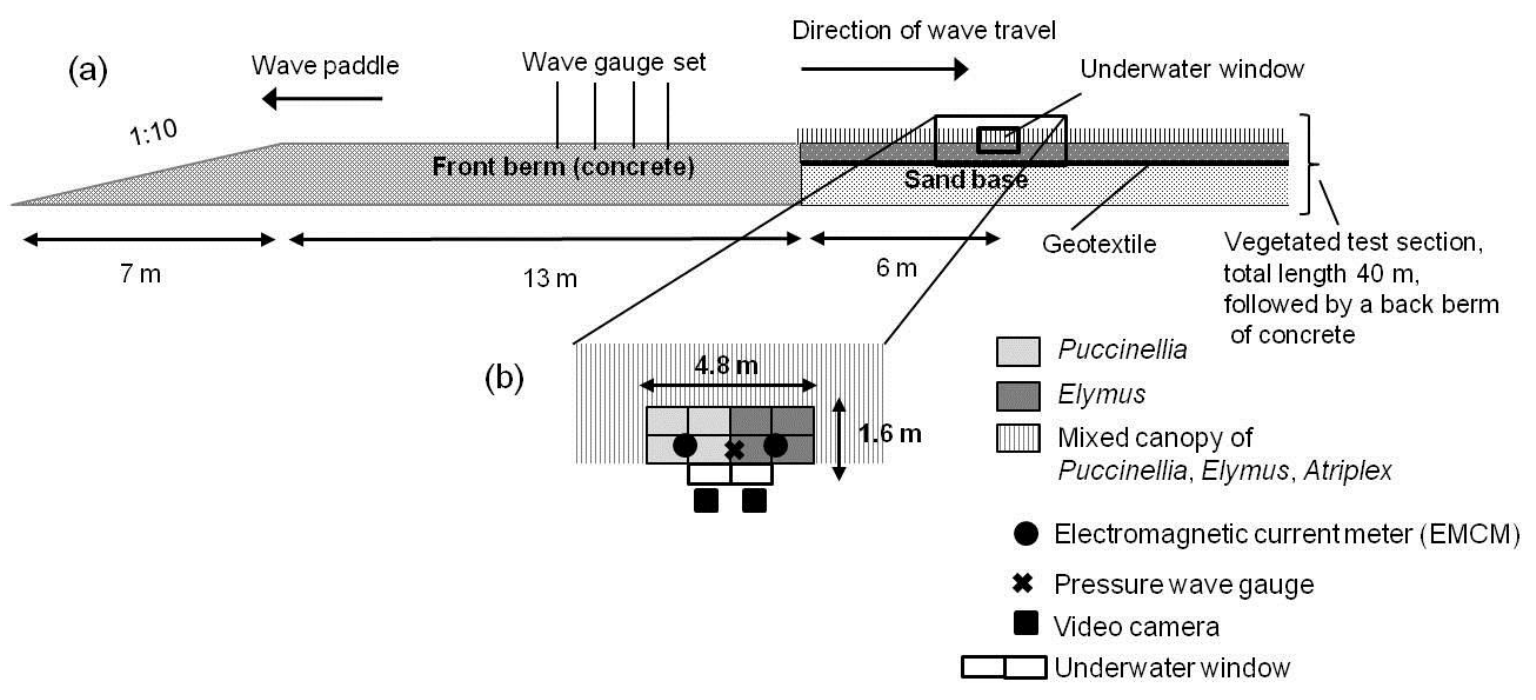

876 Fig. 2: Large scale flume experiment conducted by Möller et al. (2014). (a) General experimental 877 setup in the GWK (Großer Wellenkanal, Hannover) wave flume, (b) top view of the flume section 878 where vegetation-wave interactions in the canopy of Puccinellia and Elymus were analyzed. 
(a) Swaying movement

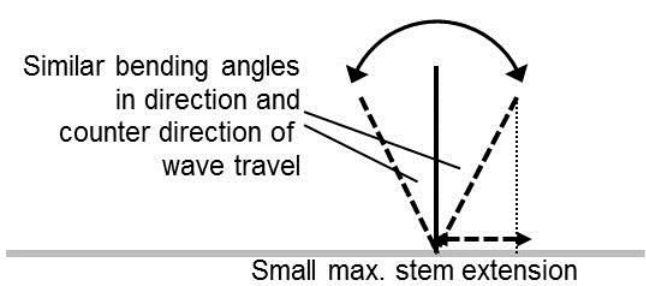

(b) Whip-like movement

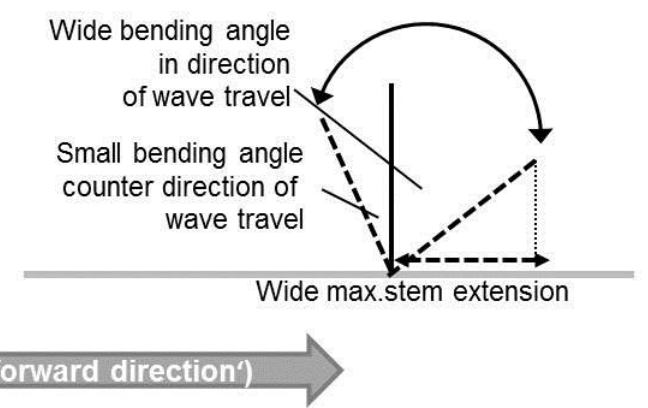

884 Fig. 2: Schematic of plant movement under wave motion. (a) Bending angles and stem extension 885 under swaying movement characteristic for low to medium orbital velocities and wave energy flux, (b) bending angles and stem extension under whip-like movement characteristic for high orbital velocities and wave energy flux. 
(a)

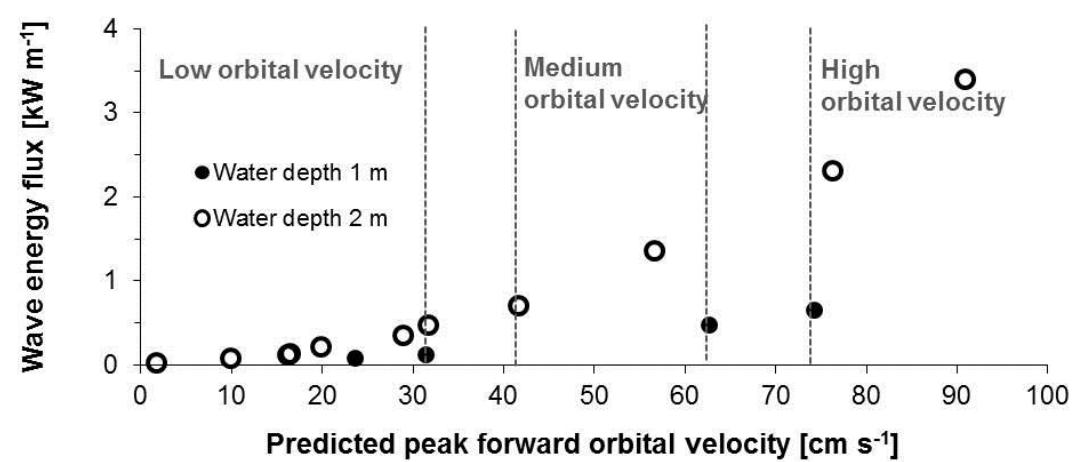

(b)

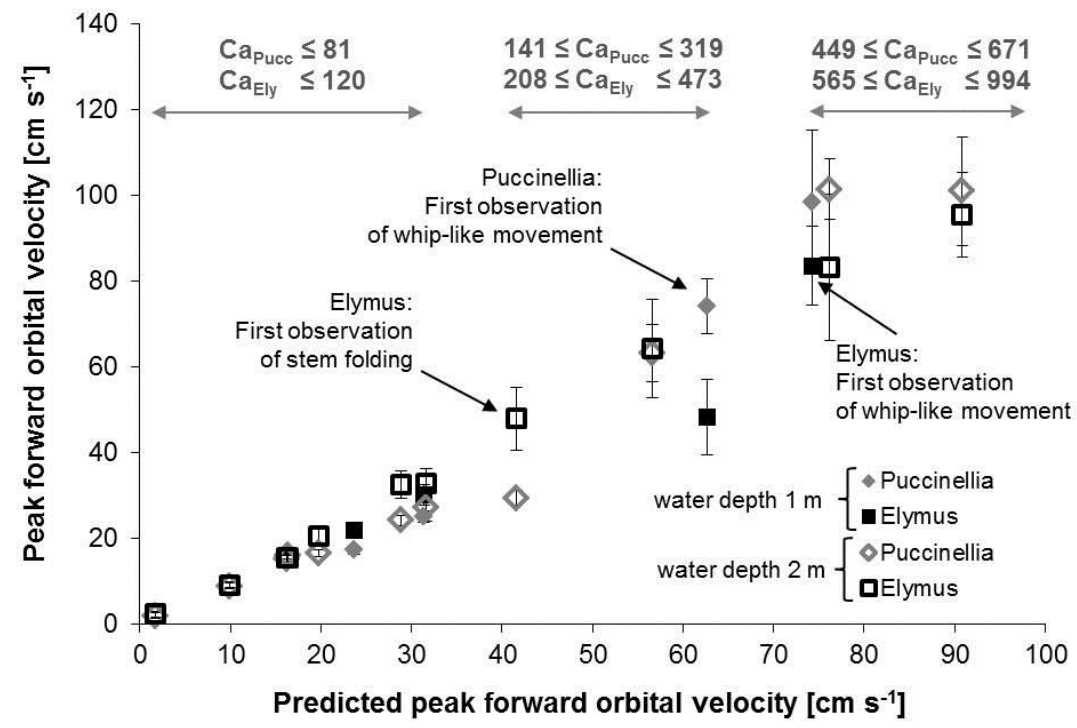

893

Fig. 4: (a) Wave energy flux as a function of the predicted peak forward orbital velocity / Relationship between predicted peak forward orbital velocity and wave energy flux and (b) measured peak forward orbital velocity in Puccinellia and Elymus and range of the Cauchy number (Ca, ratio of the hydrodynamic forcing to the restoring force due to plant stiffness) under low, medium and high predicted peak forward orbital velocity. Error bars refer to the mean \pm 1 SD of time series measurements over the complete wave test $(96 \leq \mathrm{N} \leq 148)$.

901

902 


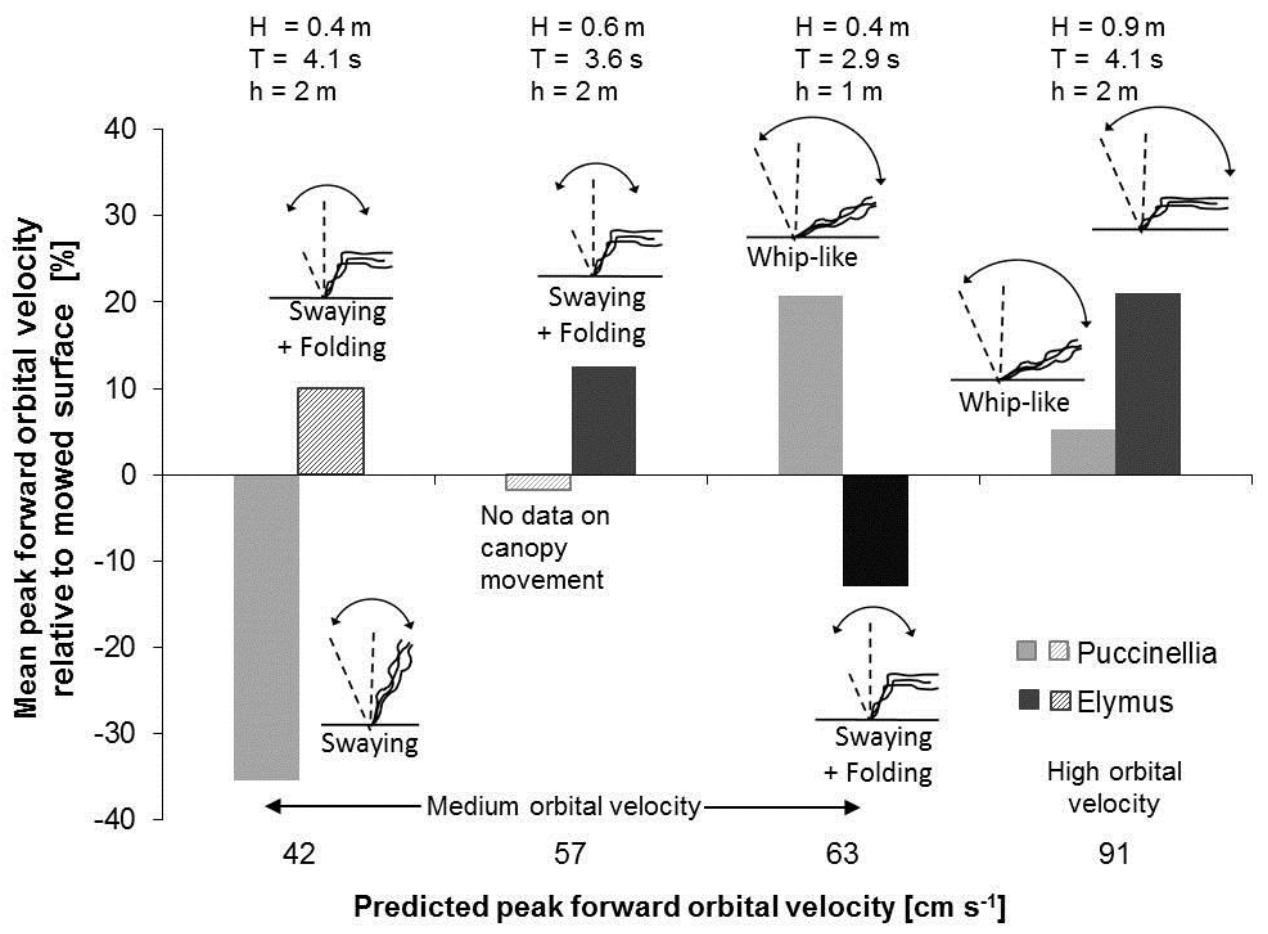

907 Fig. 5: Mean peak forward orbital velocity $\left(U_{\text {peak } f}\right)$ in Puccinellia and Elymus relative to mowed 908 conditions under low, medium and high predicted peak forward orbital velocity. Negative values 909 indicate a reduction, positive values an increase in $\left(U_{\text {peak } f}\right)$ due to presence of Puccinellia and Elymus.

910 Hatched columns indicate conditions where no significant differences (t-test; $\mathrm{p}>0.01$ ) between $U_{\text {peakf }}$ 911 under vegetated and mowed conditions were found. 


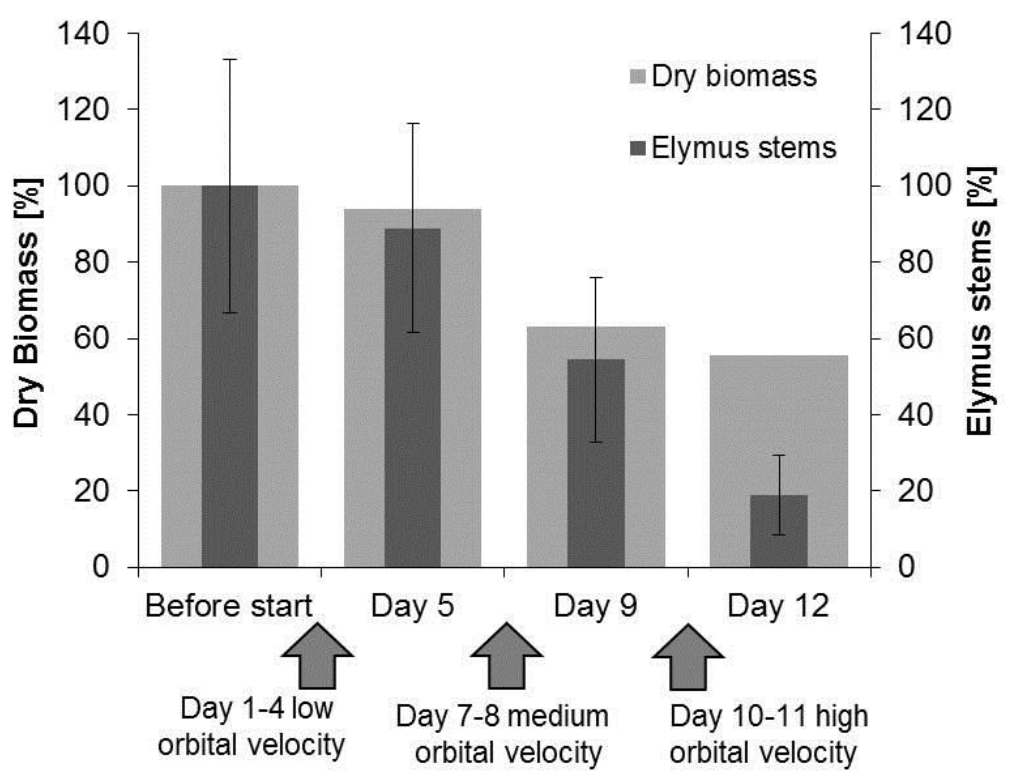

916

917 Fig. 6: Total dry plant biomass remaining on the $40 \mathrm{~m}$ vegetated test section (see Figure 2 ) in the 918 flume (light grey bars) and number of Elymus stems (dark gray, mean \pm 1 SD from $1810 \times 10 \mathrm{~cm}$ 919 quadrats distributed over the test section) prior to the first wave test (day 0 of the experiment) and 920 at the three time steps when the flume was drained in the course of the experiment (day 5, day 9 921 and day 12). 

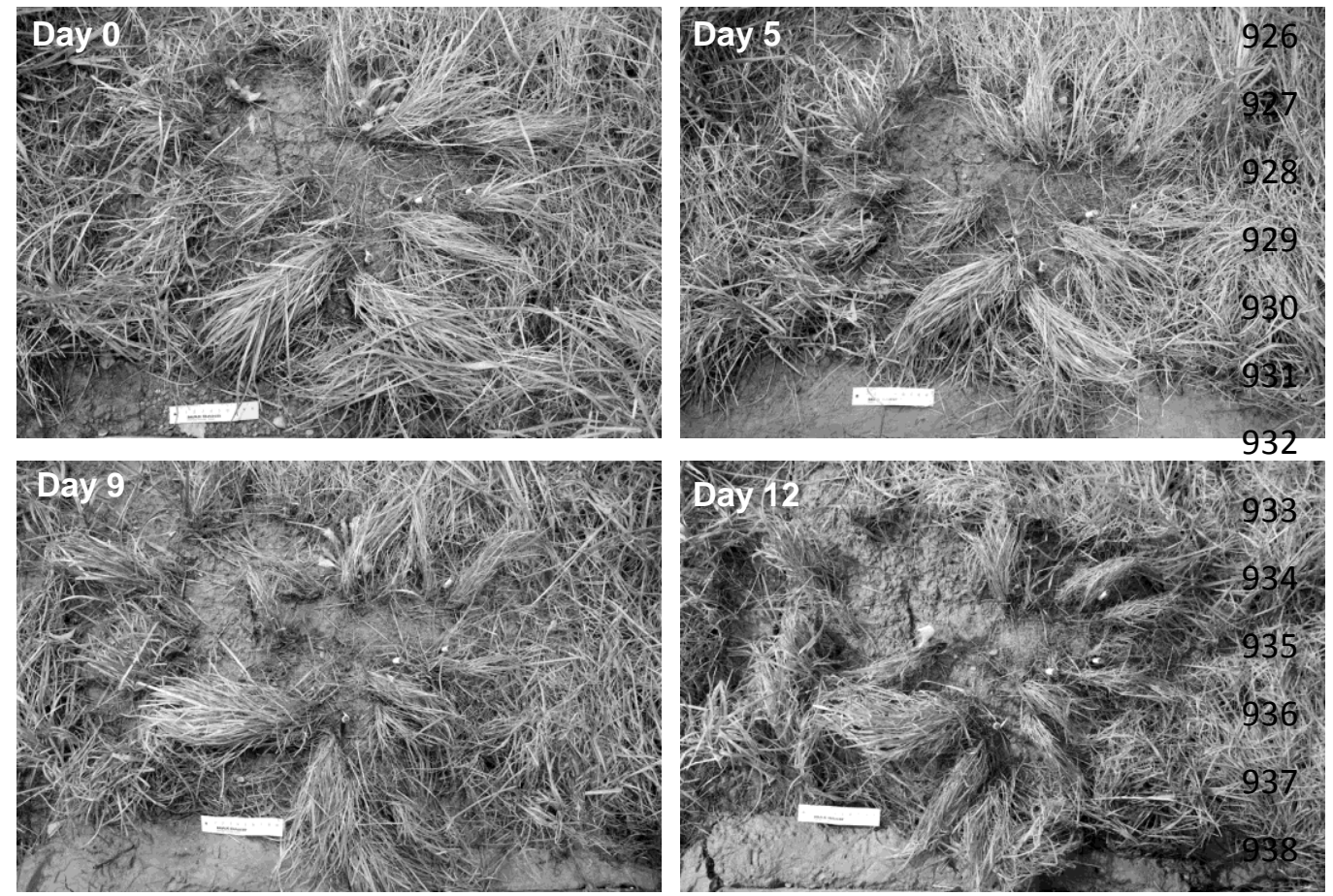

939

940 Fig. 7: Photo documentation of the Puccinellia canopy prior to the first wave test (Day 0) and at the

941 three times when the flume was drained (Day 5, 9 and 12) in the course of the experiment. The

942 photograph of Day 12 shows Puccinellia before the marsh platform was mowed i.e. at the end of 943 wave tests with the vegetated marsh surface. 


\section{Tables}

946 Table 1: Biophysical characteristics (mean values \pm 1 SD) of the Puccinellia and Elymus canopy at the

947 test section in the flume and at the field site where the marsh blocks for the flume experiment were

948 excavated. Young's bending modulus and flexural rigidity and stem diameter were measured with $\mathrm{N}$

$949=17$ for Puccinellia and $\mathrm{N}=18$ for Elymus; stem height with $\mathrm{N}=30$ and stem density with $\mathrm{N}=10$ for

950 both species.

951

952

953

954

955

956

957

\begin{tabular}{|l|l|l|l|l|l|}
\hline & $\begin{array}{l}\text { Stem flexibility } \\
\text { Young's bending } \\
\text { Modulus [MPa] }\end{array}$ & $\begin{array}{l}\text { Stem flexibility } \\
\text { Flexural rigidity } \\
{\left[\mathrm{Nm}^{2} \times 10^{-5}\right]}\end{array}$ & $\begin{array}{l}\text { Stem } \\
\text { diameter } \\
{[\mathrm{mm}]}\end{array}$ & $\begin{array}{l}\text { Stem } \\
\text { height } \\
{[\mathrm{mm}]}\end{array}$ & $\begin{array}{l}\text { Stem } \\
\text { density } \\
{[\text { number per }} \\
\left.\mathrm{m}^{2}\right]\end{array}$ \\
\hline & Mean & Mean & Mean & Mean & Mean \\
\hline $\begin{array}{l}\text { Puccinellia } \\
\text { (Flume) }\end{array}$ & $111.6 \pm 66.3$ & $0.7 \pm 0.2$ & $1.1 \pm 0.3$ & $220 \pm 30$ & - \\
\hline $\begin{array}{l}\text { Puccinellia } \\
\text { (Field) }\end{array}$ & $284.5 \pm 369.1$ & $2.1 \pm 1.7$ & $1.2 \pm 0.2$ & $180 \pm 30$ & - \\
\hline $\begin{array}{l}\text { Elymus } \\
\text { (Flume) }\end{array}$ & $2696.3 \pm 1963.8$ & $29.9 \pm 18.4$ & $1.3 \pm 0.3$ & $700 \pm 10$ & $1225 \pm 575$ \\
\hline $\begin{array}{l}\text { Elymus } \\
\text { (Field) }\end{array}$ & $2514.7 \pm 2977.1$ & $56.9 \pm 20.7$ & $1.7 \pm 0.4$ & $800 \pm 10$ & $1700 \pm 200$ \\
\hline
\end{tabular}

958

959 
960

961

962

963

964

965

966

967

968

969

970

971

972

973

974

975

976

977

978

979

980

981

Table 2: Hydrodynamic conditions simulated with regular non-breaking waves in the flume experiment. Mean wave height $(H)$, water depth above the marsh platform $(h)$, mean wave period $(T)$, energy flux per meter crest length $(P)$, mean peak forward orbital velocity predicted from wave parameters ( $\left.U_{\text {peakf pred }}\right)$ and mean peak forward and backward orbital velocity $\left(U_{\text {peakf }}, U_{\text {peak } b}\right)$ recorded within canopies of Puccinellia and Elymus. Wave tests which were repeated after mowing of the marsh platform are shaded in grey. Statistical significance of differences between Puccinellia and Elymus in in $U_{\text {peakf }}\left(\Delta U_{\text {peakf }}\right)$ and $U_{\text {peak } b}\left(\Delta U_{\text {peak } b}\right)$ verified with t-tests based on $(96 \leq \mathrm{N} \leq 148)$ waves. Non significant differences between species $(p>0.05)$ in $U_{\text {peakf }}$ and $U_{\text {peak } b}$ are marked with ' $n s$ '.

\begin{tabular}{|c|c|c|c|c|c|c|c|c|c|c|c|c|c|}
\hline \multirow[t]{2}{*}{$\begin{array}{l}\text { Test } \\
\text { no. }\end{array}$} & \multirow[t]{2}{*}{$\begin{array}{l}\text { Orbital } \\
\text { velocity } \\
\text { class }\end{array}$} & \multirow[t]{2}{*}{$\begin{array}{l}U_{\text {peakf }} \\
\text { pred } \\
{\left[\mathrm{cm} \mathrm{s}^{-1}\right]}\end{array}$} & \multirow[t]{2}{*}{$\begin{array}{l}P \\
{[\mathrm{~kW}} \\
\left.\mathbf{m}^{-1}\right]\end{array}$} & \multirow[t]{2}{*}{$\begin{array}{l}h \\
{[\mathrm{~m}]}\end{array}$} & \multirow[t]{2}{*}{$\begin{array}{l}H \\
{[\mathrm{~m}]}\end{array}$} & \multirow[t]{2}{*}{$\begin{array}{l}T \\
{[\mathbf{s}]}\end{array}$} & \multicolumn{3}{|c|}{$\begin{array}{l}U_{\text {peak } f} \\
{\left[\mathrm{~cm} \mathrm{~s}^{-1}\right](\text { mean } \pm 1 \mathrm{SD})}\end{array}$} & \multicolumn{3}{|c|}{$\begin{array}{l}U_{\text {peak b }} \\
\left.\left[\mathrm{cm} \mathrm{s}^{-1}\right] \text { (mean } \pm 1 \mathrm{SD}\right)\end{array}$} & \multirow[t]{2}{*}{ Day } \\
\hline & & & & & & & Puccinellia & Elymus & $\begin{array}{l}\Delta \\
U_{\text {peakf }}\end{array}$ & Puccinellia & Elymus & $\begin{array}{l}\Delta \\
U_{\text {peak } b}\end{array}$ & \\
\hline 1 & Low & 1.8 & 0.02 & 2 & 0.1 & 1.5 & $1.9 \pm 0.6$ & $2.3 \pm 0.6$ & 0.4 & $-2.8 \pm 0.6$ & $-2.2 \pm 0.5$ & 0.3 & 1 \\
\hline 2 & Low & 10.0 & 0.08 & 2 & 0.2 & 2.1 & $8.9 \pm 0.7$ & $9.1 \pm 0.6$ & 0.2 & $-10.4 \pm 0.7$ & $9.6 \pm 0.7$ & 0.8 & 1 \\
\hline 3 & Low & 16.2 & 0.13 & 2 & 0.2 & 2.9 & $15.2 \pm 0.8$ & $15.5 \pm 0.9$ & 0.3 & $-15.9 \pm 1.0$ & $-14.6 \pm 0.9$ & 1.3 & 1 \\
\hline 4 & Low & 16.4 & 0.13 & 2 & 0.2 & 2.9 & $16.0 \pm 0.9$ & $15.5 \pm 0.8$ & 0.5 & $-15.9 \pm 1.1$ & $-13.5 \pm 1.4$ & 2.4 & 3 \\
\hline 5 & Low & 19.8 & 0.22 & 2 & 0.3 & 2.5 & $16.5 \pm 0.8$ & $20.5 \pm 1.6$ & 4.0 & $-17.7 \pm 1.1$ & $-18.2 \pm 2.1$ & 0.5 & 3 \\
\hline 6 & Low & 23.7 & 0.07 & 1 & 0.2 & 2.1 & $17.2 \pm 1.0$ & $21.9 \pm 1.2$ & 4.7 & $-19.8 \pm 1.1$ & $-18.9 \pm 1.2$ & 1.0 & 4 \\
\hline 7 & Low & 28.8 & 0.36 & 2 & 0.3 & 3.6 & $24.2 \pm 1.2$ & $32.6 \pm 3.2$ & 8.4 & $-20.5 \pm 1.5$ & $-24.1 \pm 3.5$ & 3.6 & 3 \\
\hline 8 & Low & 31.4 & 0.12 & 1 & 0.2 & 2.9 & $25.1 \pm 1.4$ & $30.1 \pm 2.4$ & 5.0 & $-21.5 \pm 1.5$ & $-24.4 \pm 2.6$ & 2,9 & 4 \\
\hline 9 & Low & 31.6 & 0.48 & 2 & 0.4 & 2.9 & $27.2 \pm 3.1$ & $32.9 \pm 3.3$ & 5.7 & $-30.5 \pm 2.1$ & $-25.5 \pm 2.5$ & 5.0 & 7 \\
\hline 10 & Medium & 41.6 & 0.71 & 2 & 0.4 & 4.1 & $29.4 \pm 1.7$ & $47.9 \pm 7.3$ & 18.5 & $-34.1 \pm 1.8$ & $-38.9 \pm 5.4$ & 4.8 & 7 \\
\hline 11 & Medium & 56.6 & 1.36 & 2 & 0.6 & 3.6 & $63.2 \pm 6.7$ & $\begin{array}{l}64.3 \pm \\
11.5\end{array}$ & ns & $-48.6 \pm 2.4$ & $-46.7 \pm 9.4$ & ns & 7 \\
\hline 12 & Medium & 62.7 & 0.47 & 1 & 0.4 & 2.9 & $74.2 \pm 6.5$ & $48.2 \pm 8.7$ & 26.0 & $-41.5 \pm 2.9$ & $-50.5 \pm 8.7$ & 9.0 & 8 \\
\hline 13 & High & 74.3 & 0.65 & 1 & 0.5 & 3.3 & $98.5 \pm 16.8$ & $83.5 \pm 9.2$ & 5.0 & $-50.5 \pm 9.2$ & $-48.2 \pm 9.2$ & 2.3 & 11 \\
\hline 14 & High & 76.2 & 2.31 & 2 & 0.7 & 5.1 & $101.4 \pm 7.0$ & $\begin{array}{l}83.2 \pm \\
17.1\end{array}$ & 18.2 & $-41.0 \pm 3.1$ & $-37.2 \pm 10.1$ & 3.8 & 8 \\
\hline 15 & High & 90.9 & 3.39 & 2 & 0.9 & 4.1 & $100.9 \pm 12.6$ & $95.4 \pm 9.8$ & 5.5 & $-73.7 \pm 4.4$ & $62.8 \pm 9.5$ & 10.9 & 10 \\
\hline
\end{tabular}

(1) 
982 Table 3: Observed characteristics of vegetation-wave interactions, Cauchy number ( $\mathrm{Ca}$; ratio of the 983 hydrodynamic forcing to the restoring force due to plant stiffness), ratio of canopy height to wave 984 orbital excursion $(L)$ and effect of vegetation on peak forward orbital velocity $\left(U_{\text {peak } f}\right)$ in Puccinellia 985 (PuCC) and Elymus (Ely). Wave tests that were repeated after mowing of the marsh platform are 986 shaded in grey. Due to high water turbidity bending angles could not be measured for either Puccinellia or Elymus in the wave test 13 nor for Puccinellia in the wave test 11.

988

989

\begin{tabular}{|c|c|c|c|c|c|c|c|c|c|c|c|c|c|c|c|c|}
\hline \multirow[t]{2}{*}{$\begin{array}{l}\text { Test } \\
\text { no. }\end{array}$} & \multirow[t]{2}{*}{$\begin{array}{l}\text { Orbital } \\
\text { velocity } \\
\text { class }\end{array}$} & \multirow[t]{2}{*}{$\begin{array}{l}U_{\text {peak } f} \\
\text { pred } \\
{[\mathrm{cm}} \\
\left.\mathrm{s}^{-1}\right] \\
\end{array}$} & \multirow[t]{2}{*}{$\begin{array}{l}h \\
{[\mathrm{~m}]}\end{array}$} & \multirow[t]{2}{*}{$\begin{array}{l}\boldsymbol{H} \\
{[\mathrm{m}]}\end{array}$} & \multirow[t]{2}{*}{$\begin{array}{l}T \\
{[\mathrm{~s}]}\end{array}$} & \multicolumn{2}{|c|}{ Movement } & \multicolumn{2}{|c|}{$\begin{array}{l}\text { Bending angle } \\
\text { in/counter wave } \\
\text { travel }\end{array}$} & \multicolumn{2}{|l|}{$\mathrm{Ca}$} & \multirow[b]{2}{*}{$\Delta C a$} & \multicolumn{2}{|l|}{$L$} & \multicolumn{2}{|c|}{$\begin{array}{l}\text { Effect on } U_{\text {peak }} \\
\text { compared to mowed } \\
\text { conditions }\end{array}$} \\
\hline & & & & & & Pucc & Ely & Pucc & Ely & Pucc & Ely & & Pucc & Ely & Pucc & Ely \\
\hline 1 & Low & 1.8 & 2 & 0.1 & 1.5 & No & No & $\begin{array}{l}\text { upright } \\
\text { canopy }\end{array}$ & $\begin{array}{l}\text { upright } \\
\text { canopy }\end{array}$ & 0.3 & 0.4 & 0.1 & 42.9 & 166.9 & - & - \\
\hline 2 & Low & 10.0 & 2 & 0.2 & 2.1 & SW & SW & $10^{\circ} / 10^{\circ}$ & $5^{\circ} / 5^{\circ}$ & 8.0 & 11.4 & 3.9 & 5.4 & 21.0 & - & - \\
\hline 3 & Low & 16.2 & 2 & 0.2 & 2.9 & SW & SW & $20^{\circ} / 20^{\circ}$ & $10^{\circ} / 10^{\circ}$ & 21.5 & 31.8 & 10.3 & 2.4 & 9.3 & - & - \\
\hline 4 & Low & 16.2 & 2 & 0.2 & 2.9 & SW & SW & $20^{\circ} / 20^{\circ}$ & $10^{\circ} / 10^{\circ}$ & 21.8 & 32.3 & 10.5 & 2.4 & 9.2 & - & - \\
\hline 5 & Low & 19.8 & 2 & 0.3 & 2.5 & SW & SW & $20^{\circ} / 20^{\circ}$ & $10^{\circ} / 10^{\circ}$ & 31.9 & 47.2 & 15.3 & 2.3 & 8.9 & - & - \\
\hline 6 & Low & 23.7 & 1 & 0.2 & 2.1 & SW & SW & $20^{\circ} / 20^{\circ}$ & $10^{\circ} / 10^{\circ}$ & 45.6 & 67.5 & 21.9 & 2.3 & 8.8 & RED & INC \\
\hline 7 & Low & 28.8 & 2 & 0.3 & 3.6 & SW & SW & $35^{\circ} / 35^{\circ}$ & $25^{\circ} / 25^{\circ}$ & 67.80 & 100.4 & 32.6 & 1.1 & 4.2 & - & - \\
\hline 8 & Low & 31.4 & 1 & 0.2 & 2.9 & SW & SW & $35^{\circ} / 35^{\circ}$ & $15^{\circ} / 15^{\circ}$ & 80.00 & 118.5 & 38.5 & 1.2 & 4.8 & - & - \\
\hline 9 & Low & 31.6 & 2 & 0.4 & 2.9 & SW & SW & $40^{\circ} / 40^{\circ}$ & $20^{\circ} / 20^{\circ}$ & 81.4 & 120.5 & 39.1 & 1.2 & 4.8 & RED & INC \\
\hline 10 & Medium & 41.6 & 2 & 0.4 & 4.1 & SW & SW & $50^{\circ} / 50^{\circ}$ & $\begin{array}{l}\text { Stem } \\
\text { folding }\end{array}$ & 140.6 & 208.2 & 67.5 & 0.7 & 2.6 & RED & NS \\
\hline 11 & Medium & 56.6 & 2 & 0.6 & 3.6 & - & SW & - & $\begin{array}{l}\text { Stem } \\
\text { folding }\end{array}$ & 260.9 & 386.1 & $\begin{array}{r}125 . \\
3\end{array}$ & 0.6 & 2.2 & NS & INC \\
\hline 12 & Medium & 62.7 & 1 & 0.4 & 2.9 & WP & SW & $60^{\circ} / 35^{\circ}$ & $\begin{array}{l}\text { Stem } \\
\text { folding }\end{array}$ & 319.3 & 472.6 & $\begin{array}{r}153 . \\
3\end{array}$ & 0.6 & 2.4 & INC & RED \\
\hline 13 & High & 74.3 & 1 & 0.5 & 3.3 & WP & WP & - & - & 448.9 & 664.5 & $\begin{array}{r}215 . \\
6\end{array}$ & 0.5 & 1.8 & - & - \\
\hline 14 & High & 76.2 & 2 & 0.7 & 5.1 & WP & WP & $60^{\circ} / 25^{\circ}$ & $\begin{array}{l}\text { Stem } \\
\text { folding }\end{array}$ & 472.5 & 699.4 & $\begin{array}{r}226 . \\
9\end{array}$ & 0.3 & 1.1 & - & - \\
\hline 15 & High & 90.9 & 2 & 0.9 & 4.1 & WP & WP & $60^{\circ} / 25^{\circ}$ & $\begin{array}{l}\text { Stem } \\
\text { folding }\end{array}$ & 671.4 & 993.7 & $\begin{array}{r}322 . \\
4\end{array}$ & 0.3 & 1.2 & INC & INC \\
\hline
\end{tabular}

990 Abbreviations used in Table: SW = Swaying movement; WP = Whip-like movement; $R E D=$ reduction; INC = increase; 991 NS = no significant effect

992 
993

994

995

996

997

998

999

1000

1001

1002

1003

1004

1005

1006

1007

1008

1009

1010

1011

1012

1013

1014

1015

1016

1017

1018

1019

1020

1021

Table 4: Mean peak forward orbital velocity $\left(U_{\text {peak }}\right)$ within canopies of Puccinellia and Elymus and when both canopies were mowed. Statistical significance of differences between $U_{\text {peak } f}$ under vegetated and $U_{\text {peakf }}$ under mowed conditions in Puccinellia and Elymus respectively ( $\Delta U_{\text {Pucc, }} \Delta U_{\text {Ely }}$ ) was verified with t-tests based on $(96 \leq \mathrm{N} \leq 148)$ waves. Negative values of $\Delta U_{\text {Pucc }}$ and $\Delta U_{E l y}$ indicate a reduction, positive values an increase of $U_{\text {peakf }}$ due to vegetation presence. Non significant values ( $p>0.01)$ are marked with 'ns'.

\begin{tabular}{|c|c|c|c|c|c|c|c|c|c|c|c|}
\hline \multirow[t]{2}{*}{$\begin{array}{l}\text { Test } \\
\text { no. }\end{array}$} & \multirow[t]{2}{*}{$\begin{array}{l}\text { Orbital } \\
\text { velocity } \\
\text { class }\end{array}$} & \multirow[t]{2}{*}{$\begin{array}{l}U_{\text {peak f pred }} \\
{\left[\mathrm{cm} \mathrm{s}^{-1}\right]}\end{array}$} & \multirow[t]{2}{*}{$\begin{array}{l}\boldsymbol{h} \\
{[\mathrm{m}} \\
]\end{array}$} & \multirow[t]{2}{*}{$\begin{array}{l}H \\
{[\mathrm{~m}} \\
]\end{array}$} & \multirow[t]{2}{*}{$\begin{array}{l}T \\
{[\mathrm{~s}]}\end{array}$} & \multicolumn{3}{|c|}{$\begin{array}{l}\text { Puccinellia } \\
U_{\text {peak } f} \\
\left.\left[\mathrm{~cm} \mathrm{~s}^{-1}\right] \text { (mean } \pm 1 \mathrm{SD}\right)\end{array}$} & \multicolumn{3}{|c|}{$\begin{array}{l}\text { Elymus } \\
U_{\text {peakt }} \\
{\left[\mathrm{cm} \mathrm{s}^{-1}\right](\text { mean } \pm 1 \mathrm{SD})}\end{array}$} \\
\hline & & & & & & vegetated & mowed & $\Delta U_{\text {Pucc }}$ & Vegetated & mowed & $\Delta U_{\text {Ely }}$ \\
\hline 6 & Low & 24.7 & 1 & 0.2 & 2.1 & $17.2 \pm 1.0$ & $21.0 \pm 1.8$ & -3.8 & $21.9 \pm 1.2$ & $19.5 \pm .3$ & 2.4 \\
\hline 9 & Low & 31.6 & 2 & 0.4 & 2.9 & $27.2 \pm 3.1$ & $33.6 \pm 3.1$ & -6.4 & $32.9 \pm 3.3$ & $27.2 \pm .5$ & 5.7 \\
\hline 10 & Medium & 42.3 & 2 & 0.4 & 4.1 & $29.4 \pm 1.7$ & $45.6 \pm 2.0$ & -16.2 & $47.9 \pm 7.3$ & $43.5 \pm .7$ & ns \\
\hline 11 & Medium & 58.3 & 2 & 0.6 & 3.6 & $63.2 \pm 6.7$ & $64.4 \pm 3.6$ & ns & $64.3 \pm 1.5$ & $57.2 \pm .5$ & 7.1 \\
\hline 12 & Medium & 61.9 & 1 & 0.4 & 2.9 & $74.2 \pm 6.5$ & $61.4 \pm 3.5$ & 12.8 & $48.2 \pm 8.7$ & $55.3 \pm .0$ & -7.1 \\
\hline 15 & High & 90.1 & 2 & 0.9 & 4.1 & $100.9 \pm 2.6$ & $96.0 \pm 5.6$ & 4.9 & $95.4 \pm 9.8$ & $78.9 \pm .9$ & 16.5 \\
\hline
\end{tabular}

(1) 


\section{Appendix}

A.1
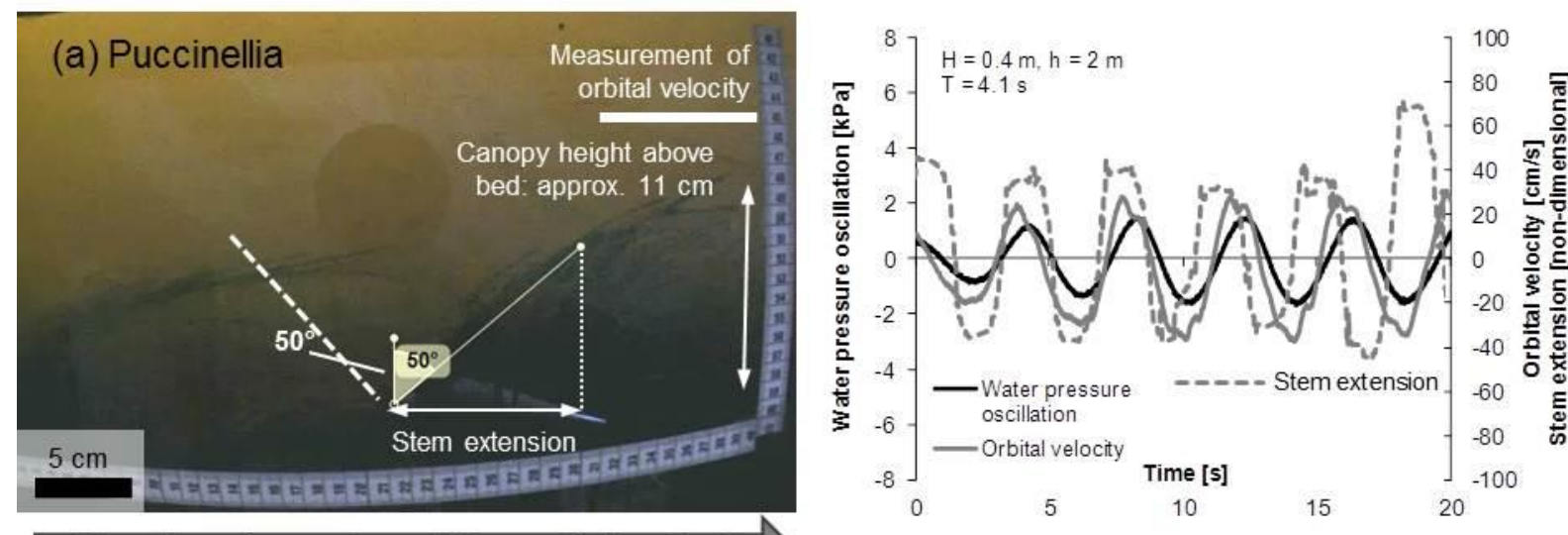

Direction of wave travel ('forward' direction)
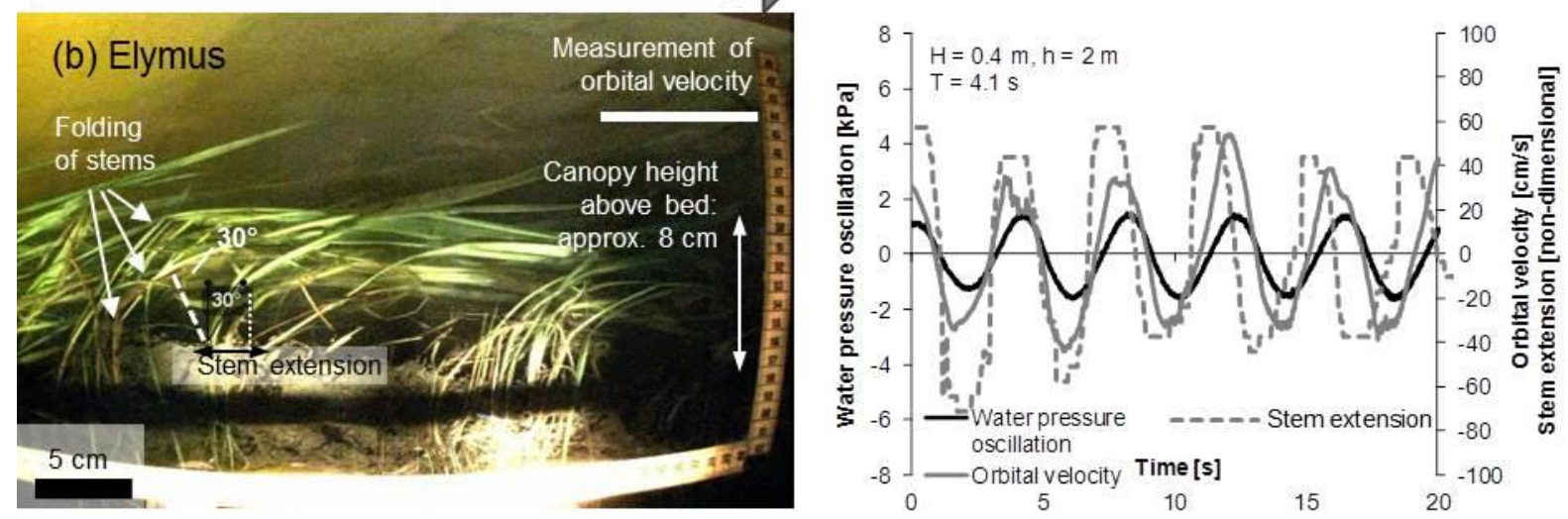

Fig. A.1: Vegetation-wave interactions under medium orbital velocity (predicted peak forward orbital velocity $42 \mathrm{~cm} \mathrm{~s}^{-1}$ ), water depth $(\mathrm{h})=2 \mathrm{~m}$, wave height $(H)=0.4 \mathrm{~m}$ and wave period $(T)=4.1 \mathrm{~s}$ (wave test 10 , Table 2). Water pressure (left y-axis), orbital velocity and time trace of horizontal stem extension (right y-axis; positive values in the direction of wave motion). (a) Swaying movement of the Puccinellia canopy and (b) Swaying movement of the Elymus canopy, both recognizable from similar bending angles and orbital velocities in forward and backward direction of wave-induced oscillatory flow. Note that due to stem folding lower stem parts of Elymus bent to smaller angles $\left(30^{\circ}\right)$ than upper more flexible stem parts resulting in bending angles of $90^{\circ}$ of the Elymus canopy as a whole Mean peak forward orbital velocity in Puccinellia with its intact stems was $40 \%$ lower than in Elymus where folding of stems occurred (see Fig. 4). 

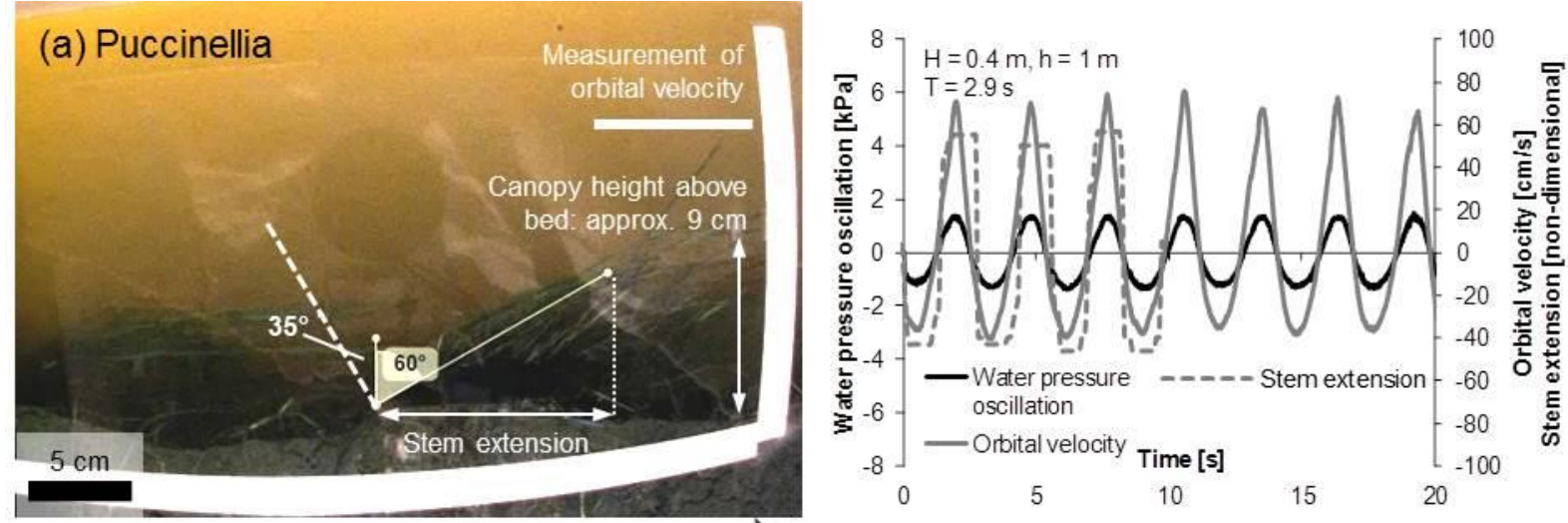

Direction of wave travel ('forward' direction)
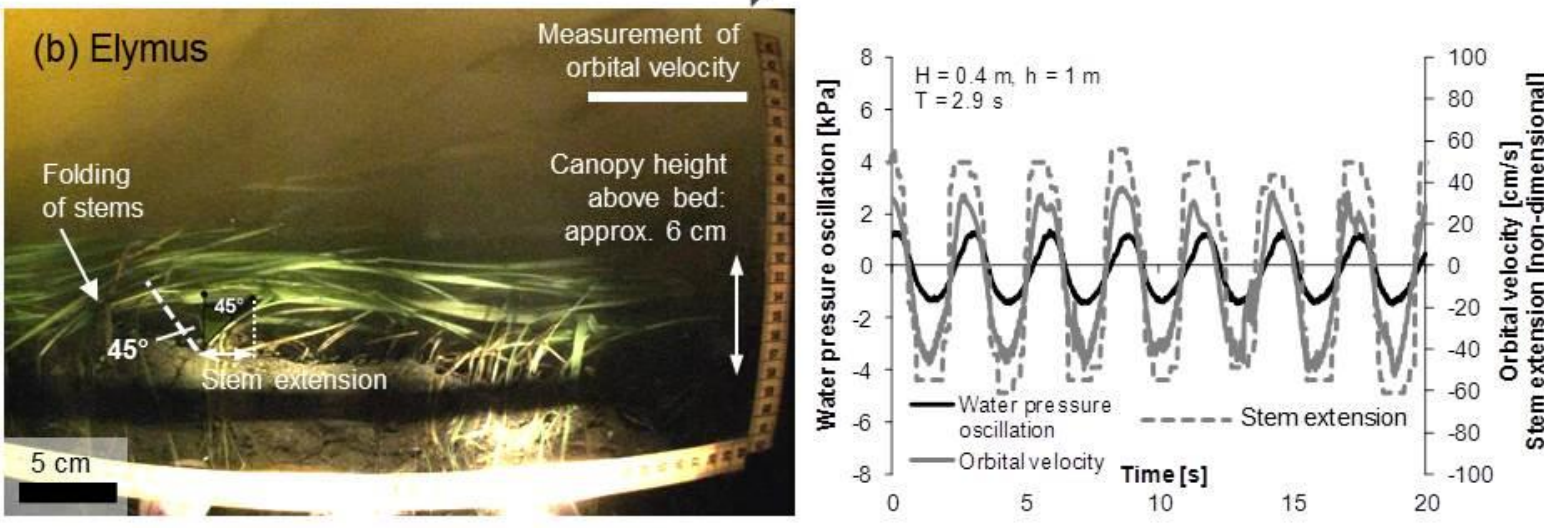

Fig. A.2: Vegetation-wave interactions under medium orbital velocity (predicted peak forward orbital velocity $63 \mathrm{~cm} \mathrm{~s}^{-1}$ ) water depth $(\mathrm{h})=1 \mathrm{~m}$, wave height $(H)=0.4 \mathrm{~m}$ and wave period $(T)=2.9 \mathrm{~s}$ (wave test 12 , Table 2). Water pressure (left y-axis), orbital velocity and time trace of horizontal stem extension (right y-axis; positive values in direction of wave motion). (a) Whip-like movement of the Puccinellia canopy recognizable from wide bending angles and high orbital velocity in forward direction of wave-induced oscillatory flow. (b) Swaying movement of the Elymus canopy recognizable from similar bending angles and orbital velocities in forward and backward direction of wave-induced oscillatory flow. Note that due to stem folding lower stem parts of Elymus bent to smaller angles $\left(45^{\circ}\right)$ than upper more flexible stem parts resulting in bending angles of $90^{\circ}$ of the Elymus canopy as a whole. Following its whip-like movement mean peak forward orbital velocity in Puccinellia was approx. 50\% higher than in Elymus (see Fig. 4). 

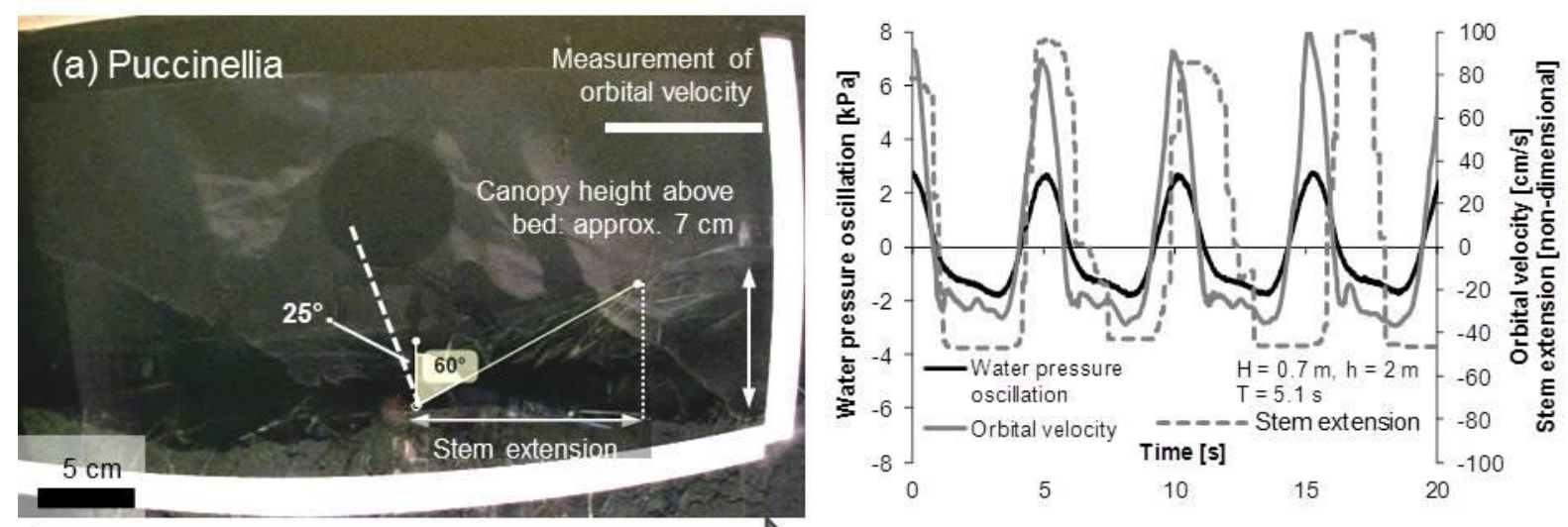

Direction of wave travel ('forward' direction
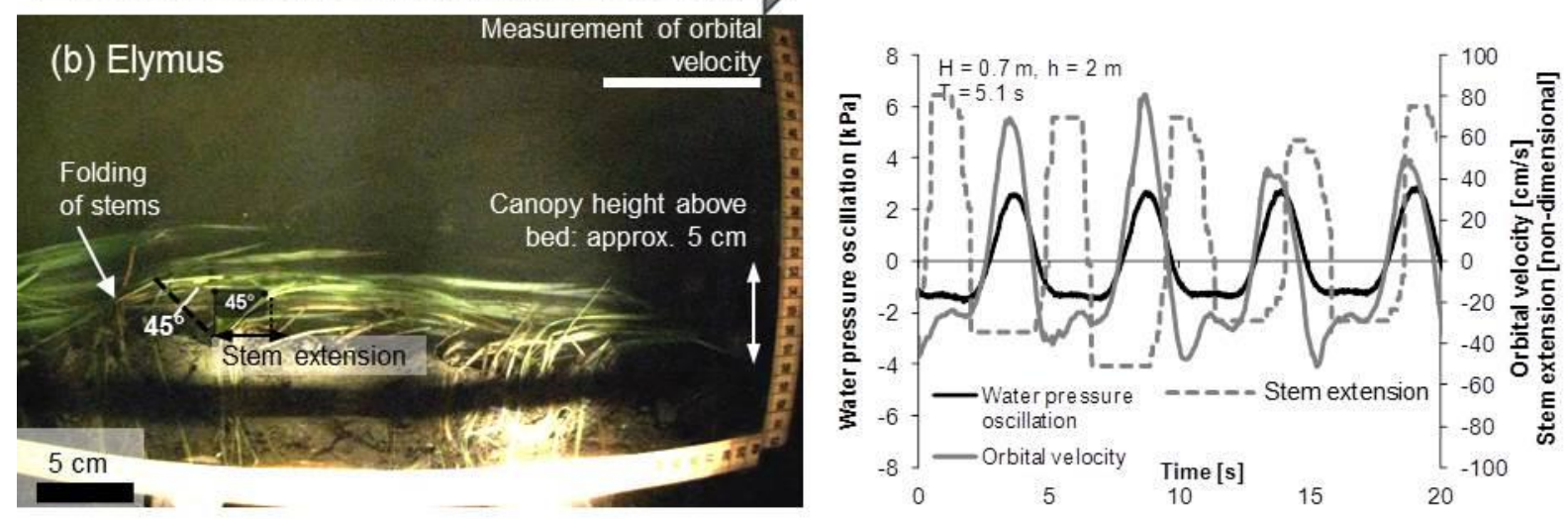

1059

Fig. A.3: Vegetation-wave interactions under high orbital velocity (predicted peak forward orbital velocity $76 \mathrm{~cm} \mathrm{~s}^{-1}$ ) water depth $(\mathrm{h})=2 \mathrm{~m}$, wave height $(H)=0.7 \mathrm{~m}$ and wave period $(T)=5.1 \mathrm{~s}$ (wave test 14, Table 2). Water pressure (left y-axis), orbital velocity and time trace of horizontal stem extension (right $y$-axis; positive values in the direction of wave motion). (a) Whip-like movement of the Puccinellia canopy and (b) whip-like movement of the Elymus canopy, both recognizable from wide bending angles and high orbital velocity in forward direction of wave-induced oscillatory flow. Note that due to stem folding lower stem parts of Elymus bent to smaller angles $\left(45^{\circ}\right)$ than upper more flexible stem parts resulting in bending angles of $90^{\circ}$ of the Elymus canopy as a whole. Mean peak forward orbital velocity in Puccinellia was $20 \%$ higher than in Elymus (see Fig. 4). One reason for this may be the lower phase difference between canopy movement and water motion in Puccinellia. 